\title{
LA PARTICIPACIÓN DE LA UNIÓN EUROPEA EN ORGANIZACIONES INTERNACIONALES EN TIEMPOS DE BREXIT
}

\author{
CARMELA PÉREZ BERNÁRDEZ
}

carmelapb@ugr.es

\author{
Cómo citar/Citation \\ Pérez Bernárdez, C. (2020). \\ La participación de la Unión Europea en Organizaciones \\ Internacionales en tiempos de Brexit. \\ Revista de Derecho Comunitario Europeo, 67, 963-1005. \\ doi: https://doi.org/10.18042/cepc/rdce.67.06
}

\section{Resumen}

Este trabajo realiza una aproximación a una de las manifestaciones más sobresalientes de la acción exterior de la Unión Europea, en concreto, su participación en organizaciones internacionales. En ese contexto, como aspecto novedoso, se estudia la incidencia jurídico-política que la retirada del Reino Unido (RU) de la Unión Europea está teniendo en las relaciones de ambos con las organizaciones internacionales. Ante el incierto panorama que plantea el Brexit, se analizan los escenarios posibles, la normativa aplicable y la negociación tendente a alcanzar un acuerdo UE-RU que regule sus relaciones tras el periodo transitorio. El estudio identifica ciertas pautas

1 Profesora titular del Departamento de Derecho Internacional Público y Relaciones Internacionales de la Universidad de Granada. Trabajo realizado en el marco de los Proyectos de $\mathrm{I}+\mathrm{D}+\mathrm{i}$ sobre «La acción exterior de la UE y el Estado de derecho» (ACEXDE), RTI2018-101041-B-I00, Ministerio de Ciencia, Innovación y Universidades (del que es coinvestigadora principal) y «La redefinición de la acción exterior de la UE tras el Brexit» (EU-EXTERNAL), A-SEJ-299-UGR18, programa operativo FEDER 2018. 
previsibles en las distintas categorías de participación de la UE y del RU en organizaciones internacionales. La concreción e intensidad de los ajustes a realizar, por ejemplo, en los derechos inherentes a la condición de miembro quedarán afectados por las singularidades propias de cada organización internacional, así como por la situación política. El análisis defiende que la UE se encuentra en una posición privilegiada en la mayoría de las organizaciones internacionales - que ha ido consolidando progresivamente a través de sus Tratados, la jurisprudencia y la práctica- para adaptarse y afianzarse como actor internacional, en un contexto en el que el Brexit aparece como un exponente de la crisis del multilateralismo institucional.

\section{Palabras clave}

Unión Europea; organizaciones internacionales; brexit; Reino Unido; multilateralismo.

\section{THE EUROPEAN UNION'S PARTICIPATION IN INTERNATIONAL ORGANIZATIONS IN TIMES OF BREXIT}

\section{Abstract}

This article approaches one of the most outstanding manifestations of the European Union's external action, namely its participation in International Organizations. In this context, as a novel aspect, we study the legal-political impact that the United Kingdom's withdrawal from the European Union is having on their relationships with International Organizations.

Facing the uncertain panorama posed by Brexit, this article examines the possible scenarios, the applicable regulations and the negotiations aimed at reaching an EU-UK Agreement that regulates their relations after the transitional period. The study identifies certain predictable patterns in the various categories of EU and UK participation in International Organizations. The specificity and intensity of the adjustments to be made (for example, in the rights inherent in membership) will be affected by the peculiarities of each International Organization, as well as by the political context. The analysis argues that the EU is in a privileged position in the majority of International Organizations — which has been progressively consolidated through its Treaties, jurisprudence and practice — to adapt and affirm itself as an international actor, in a context in which Brexit appears as an illustration of the crisis of institutional multilateralism.

\section{Keywords}

European Union; International Organizations; Brexit; United Kingdom; multilateralism. 


\section{LA PARTICIPATION DE L'UNION EUROPÉENNE DANS LES ORGANISATIONS INTERNATIONALES DANS LE CONTEXTE DU BREXIT}

Résumé

Ce travail effectue une approche de l'une des manifestations les plus marquantes de l'action extérieure de l'Union Européenne, notamment, sa participation aux organisations internationales. Dans ce contexte, en tant qu'aspect nouveau, l'impact juridico-politique que le retrait du Royaume-Uni de l'Union Européenne a sur leurs relations avec les organisations internationales est étudié. Compte tenu du panorama incertain posé par le Brexit, les scénarios possibles, les réglementations applicables et la négociation visant à parvenir à un Accord UE-Royaume-Uni qui réglemente leurs relations après la période de transition sont analysés. L'étude identifie certains modèles prévisibles dans les différentes catégories de participation de l'UE et du Royaume-Uni aux organisations internationales. La spécificité et l'intensité des ajustements à apporter, par exemple, dans les droits inhérents à l'adhésion, seront affectées par les particularités de chaque organisation internationale, ainsi que par la situation politique.

L'analyse préconise que l'Union Européenne se trouve dans une position privilégiée dans la majorité des organisations internationales — qui s'est progressivement consolidée par le biais de ses Traités, la jurisprudence et la pratique- pour s'adapter et s'affirmer en tant qu'acteur international, dans un contexte où le Brexit apparaît comme une illustration de la crise du multilatéralisme institutionnel.

\section{Mots clés}

Union Européenne; Organisations Internationales; Brexit; Royaume-Uni; multilatéralisme. 


\section{SUMARIO}

I. INTRODUCCIÓN. II. EL (BUEN) ESTADO ACTUAL DE LA UNIÓN EUROPEA EN LAS ORGANIZACIONES INTERNACIONALES. III. EL IMPACTO JURÍDICO-POLÍTICO DEL BREXIT: 1. En el periodo transitorio: 1.1 El Acuerdo de Retirada. 1.2. Un plan de contingencia. 2. En el periodo posterior al transitorio: 2.1. Escenarios y normativa. 2.2. Hacia un acuerdo de partenariado post-Brexit. 2.3. Categorías de participación de la UE y del RU en organizaciones internacionales. IV. REFLEXIONES FINALES. BIBLIOGRAFíA.

\section{INTRODUCCIÓN}

El objeto de este trabajo es realizar una aproximación a una de las manifestaciones más sobresalientes de la acción exterior de la Unión Europea; en concreto, la que desarrolla en su condición de miembro y observador en el seno de distintas organizaciones internacionales, agregando una perspectiva actual que ha sido abordada tímidamente por la doctrina, esta es, la incidencia de la retirada del Reino Unido (RU) de la Unión Europea (UE) en los planos jurídico y político en este contexto.

El arduo proceso de retirada, extendido durante cuatro años desde el referéndum británico en 2016, pone de manifiesto las diferencias que plantea la salida de un Estado de la Unión Europea, como organización internacional singular que es, en relación con otras. Ello es debido al carácter supranacional de la UE y, por ende, a la mayor complejidad que implica la condición de miembro, lo que problematiza el proceso de desvinculación de uno de sus Estados $^{2}$. El Acuerdo de Retirada celebrado entre la UE y el Reino Unido,

2 El art. 50 TUE, introducido en la reforma operada por el Tratado de Lisboa hace más de una década, establece expresamente la posibilidad de que un Estado miembro se retire de la UE (apdo. 1), así como el procedimiento a seguir a tal fin (apdos. 2 a 4). En el referéndum celebrado el 23 de junio de 2016, los ciudadanos británicos votaron ajustadamente a favor de abandonar la Unión Europea con un resultado del 51,9 \% a favor (leave) y un 48,1\% en contra (remain). La notificación oficial al Consejo Europeo por parte del Reino Unido de su intención de retirarse conforme al art. 50.2 TUE tuvo lugar el 29 de marzo de 2017, activándose desde ese momento el procedimiento 
en vigor desde febrero de 2020, llegó tras un periodo de incertidumbre sobre su viabilidad. Una de las principales virtualidades del acuerdo es que fija un periodo transitorio — hasta finales de 2020 — en el que el derecho de la Unión se sigue aplicando a ese Estado (de acuerdo con su art. 127) ${ }^{3}$, permitiendo el status quo de las relaciones de la UE con organizaciones internacionales sin prácticamente ajustes.

En este estudio realizamos primero un balance del estado actual de la participación de la UE en las organizaciones internacionales (apdo. II.), como punto de partida para abordar el impacto jurídico-político del Brexit en este contexto (apdo. III). Con tal fin, examinamos tanto el periodo transitorio (1.) como los posibles escenarios que se presentan en el periodo posterior a este (2.), dependientes del resultado de las negociaciones tendentes a conseguir un Acuerdo de partenariado que regule las relaciones entre la UE y el RU post-Brexit ${ }^{4}$ — esto es, con posterioridad a la finalización de la fase transitoria-.

La retirada del Reino Unido de la UE — como derecho inherente a la condición de miembro (Sobrino Heredia, 2010: 94) — muestra sus efectos con ramificaciones diversas en la membresía tanto de la UE como de la del Reino Unido en las organizaciones internacionales, así como los ajustes de intensidad variable a los que la UE y otros sujetos del derecho internacional se enfrentan, dependiendo de cada organización internacional. De ellos daremos cuenta examinando las distintas categorías de participación con el fin de identificar ciertas pautas previsibles para la UE y el RU en organizaciones internacionales. Todo ello en un periodo intenso y desafiante por distintos

formal de negociaciones. Sobre el iter enmarañado de retirada del RU de la UE desde el referéndum, véase Sobrino Heredia (2020: 281-285, 298). Sobre las singularidades de una retirada de un Estado miembro de la UE en comparativa con otras organizaciones internacionales: Wessel (2016: 201-205), así como de un posible regreso del RU a la UE: Schermers y Blokker (2018: 116, 1262).

3 El Acuerdo sobre la Retirada del Reino Unido de Gran Bretaña e Irlanda del Norte de la Unión Europea y de la Comunidad Europea de la Energía Atómica (Acuerdo de Retirada, AR a partir de ahora) fue firmado el 24 de enero de 2020, entrando en vigor con celeridad a la semana siguiente (DO L 29, de 31 de enero de 2020, pp. 7-187). Su lacónico art. 127.1 señala: «Salvo disposición en contrario del presente Acuerdo, el Derecho de la Unión será aplicable al y en el Reino Unido durante el periodo transitorio".

4 En el momento de cerrar este trabajo existe una gran incertidumbre sobre si habrá un soporte convencional que regule a inicios de 2021 las relaciones futuras entre la UE y el RU. La última fecha de consulta de las fuentes electrónicas ha sido el 6 de noviembre de 2020 . 
factores, entre ellos el auge de los populismos y nacionalismos dentro y fuera de Europa, la mayor polarización política en el seno de algunos Estados, la pandemia global de la COVID-19 y el cuestionamiento del multilateralismo institucional, del que el Brexit constituye uno de sus exponentes (Brölmann et al., 2018: 258).

\section{EL (BUEN) ESTADO ACTUAL DE LA UNIÓN EUROPEA EN LAS ORGANIZACIONES INTERNACIONALES}

La UE participa en calidad de miembro en organizaciones internacionales dedicadas a ámbitos materiales bien variados como pesquerías, comercio, productos básicos y materias primas, entre otras, como en la Organización de las Naciones Unidas para la Agricultura y Alimentación (FAO), la Organización Mundial Comercio (OMC) o la Organización de Pesquerías del Atlántico Noroeste (OPANO), ya sea de forma exclusiva — que es menos frecuente- o mixta — conjuntamente con sus Estados miembros—. Asimismo, la Unión en su condición de observadora — cada vez más privilegiada — desarrolla una actividad también relevante en varias organizaciones internacionales $-\mathrm{y}$ órganos-, por ejemplo, en la Asamblea General de las Naciones Unidas (AGNU), la Organización Marítima Internacional (OMI), la Organización para la Aviación Civil Internacional (OACI), la Organización Mundial de la Salud (OMS), el Consejo de Europa, el Consejo de Derechos Humanos en el marco de Naciones Unidas $(\mathrm{NU})$ o en otros órganos, valiéndose asimismo de la participación de sus Estados, como en el Consejo de Seguridad de las Naciones Unidas (CSNU).

La participación de la Unión en organizaciones internacionales constituye una manifestación de su subjetividad jurídica internacional que, cuantitativa y cualitativamente, caracteriza a la Unión frente a otras organizaciones internacionales.

Realizar un balance global sobre el estado actual de la UE en sus relaciones con otras organizaciones internacionales resulta complejo por distintos motivos: su amplio número y las singularidades propias de cada una - existen más de trescientas—, los distintos tipos de participación que la Unión Europea mantiene en ellas en calidad de miembro u observador, con diferente intensidad en cada caso, o el hecho de que dichas participaciones se encuentran en evolución por distintos condicionantes jurídicos y políticos internos (de la propia UE y sus Estados miembros) y externos (de la organización internacional en cuestión y de los Estados que forman parte de esta). A ello se une, en ocasiones, la dificultad para confirmar el estatuto específico de la Unión en ciertas organizaciones internacionales, por la falta de transparencia que existe en torno a ciertas actuaciones informales y privilegiadas en el 
seno de algunas de ellas o por la visibilidad escasa sobre esta participación de la UE en determinados foros institucionales 5 .

Las relaciones entre la UE y las organizaciones internacionales pueden articularse sistemáticamente a través de los tres cauces siguientes ${ }^{6}$. El más simple y primigenio se basa en relaciones de carácter administrativo entre la UE (antes Comunidad Europea o Económica Europea) y organizaciones internacionales, con obligaciones básicas de intercambio de información ${ }^{7}$, basadas, primero, en meros canjes de notas, que han ido evolucionando hacia fórmulas convencionales de mayor complejidad. Un ius ad tractatum con una incidencia compleja y variable, dependiendo del caso, que ha conseguido un desarrollo espectacular teniendo en cuenta que la Unión no es un sujeto estatal. Otra vía de relación entre la UE y las organizaciones internacionales la constituye el envío de representantes de la Unión Europea — actualmente

5 Por ejemplo, en el seno del Consejo Ártico, donde la UE goza de un estatuto de observador oficioso o de facto. La UE solicitó la condición oficial de observador ya en 2013 en la reunión ministerial de Kiruna y, aunque el resultado de dicha petición fue afirmativo, este quedó sujeto a confirmación de la decisión final de los Ministros de Asuntos Exteriores del Ártico. Después de estos años continúa sin responder por el rechazo de dos Estados de este foro internacional por cuestiones de naturaleza política de fondo: Canadá, por la prohibición de la UE del comercio de la piel y los productos derivados de la foca, y Rusia por las sanciones impuestas por la Unión tras la anexión de Crimea y la situación en Ucrania (Cinelli, 2019: 478). Sobre la evolución de la naturaleza jurídica del Consejo Ártico, como foro de cooperación intergubernamental circumpolar, y las limitaciones que ésta plantea en su proyección externa, incluyendo en sus relaciones con organizaciones internacionales, como la UE, véase Sánchez Ramos (2017: 144-145, 154). Una mayor transparencia sobre el proceso de participación de la UE en el Consejo Ártico no ha sido posible, aduciendo la Unión la necesidad salvaguardar su estrategia negociadora en dicho foro.

6 Liñán Nogueras (2020: 559-562); Odermatt y Wessel (2019: 662-666). Estos dos últimos autores incluyen otras vías más específicas, como la compliance en relación con el cumplimiento de normas, la vinculada a la arquitectura de la gobernanza global o el interregionalismo como nexo entre la UE con grupos regionales.

7 Un ejemplo extremo y revelador de la importancia del intercambio de información adecuado en el marco de organismos internacionales se produjo en junio de 2020, cuando un fallo de coordinación entre las misiones de la UE (EUNAVFOR MED Irini) y de la OTAN (Sea Guardian) en el Mediterráneo, ocasionó indirectamente un incidente entre dos de sus miembros, Francia y Turquía, apuntando esta con armas a una fragata francesa que formaba parte del operativo de la OTAN. Turquía había solicitado un mes antes del incidente que se prescindiera del oficial de enlace de la UE en el cuartel aliado de la OTAN de Northwood (Reino Unido), sede de la misión Sea Guardian, no encontrándose este en su puesto cuando tuvo lugar el incidente (González, 2020: 4). 
con estatuto de diplomático-, así como la recepción de representantes con este rango procedentes de terceros Estados y otras organizaciones internacionales ${ }^{8}$. Un ius legationis de la UE que se ha ido reforzando progresivamente, proporcionándole una mayor visibilidad en las organizaciones internacionales ante las que se acredita - y del que se ha beneficiado el Reino Unido hasta su retirada de la Unión-. El tercer cauce es el relativo a la participación de la UE en organizaciones internacionales — que en el contexto del Brexit analizamos en el epígrafe siguiente-. Este constituye el más evolucionado de los mencionados y el que mayores problemas plantea en la práctica institucional, teniendo en cuenta el carácter sui generis de cada organización internacional.

Algunas consideraciones que permiten una comprensión más integral de la evolución y desafíos de la participación de la UE en organizaciones internacionales pueden sintetizarse de la siguiente manera:

La UE intenta adquirir la condición de miembro en una organización internacional no solo por el mero hecho de tener un interés en el ámbito desarrollado en el organismo en cuestión, sino porque en él posee competencias, generalmente, de forma compartida con sus Estados miembros?.

8 Véanse, en el marco del derecho de legación activo los arts. 27.3 TUE sobre el Servicio Europeo de Acción Exterior (SEAE) y 221 TFUE en relación con las delegaciones de la UE, también, ante organizaciones internacionales, proporcionándoles un especial soporte.

9 Son números los ejemplos de organizaciones internacionales en las que, pese a tener la UE competencias en los ámbitos de trabajo de las mismas de acuerdo con su tratado constitutivo, aún no ha conseguido la condición de miembro. Esto sucede, por ejemplo, en la Agencia Internacional de la Energía Atómica (AIEA), la OMI, la Organización para la Aviación Civil Internacional (OACI), la Organización Internacional de la Viña y del Vino (OIV) o en instituciones como el Alto Comisionado de las NU para los Refugiados (ACNUR). En los últimos años la UE ha ido reforzando su marco regulador para mantener una cooperación institucional más sólida en materia de migración en el ACNUR y en la Organización Internacional para las Migraciones (OIM) (Beqiraj et al., 2019: 220). En todas las organizaciones internacionales mencionadas supra los Estados miembros de la UE mantendrían su membresía, tras una hipotética intensificación de la participación de la Unión como miembro. Existen organizaciones internacionales en las que no se permite la participación de terceros (Estados u otras organizaciones internacionales) en sus órganos; la UE es una de ellas, como otras que tienden a consolidarse como organizaciones de integración (económica) (sub)regionales — como el MERCOSUR, la Comunidad Andina de Naciones (CAN) o la Asociación de Naciones del Sudeste Asiático (ASEAN)_. Ello no obsta a que entre ellas se desarrollen vínculos estrechos a través de otras vías (ius legationis o ius ad tractatum). 
Constituye, por tanto, una «necesidad funcional» más que una aspiración general (Kaddous, 2015: 21). La complejidad del reparto competencial en las estructuras institucionales internacionales — tanto en aquellas en las que la UE es miembro, como en las que no disfruta de dicho estatuto- ha llevado al TJUE en numerosos asuntos a identificar una obligación de unidad de representación de la Unión, que dimana fundamentalmente de la obligación de cooperación leal (art. 4.3 TUE) ${ }^{10}$.

Las referencias expresas a organizaciones internacionales que se han ido incorporando a los Tratados (derecho primario de la UE) no son meras fórmulas declarativas vacías de contenido. Al contrario, aquellas permiten un rastreo de las necesidades jurídicas institucionales de la Unión generadas a lo largo tiempo y ponen de manifiesto la mayor relevancia que algunas organizaciones internacionales adquieren para la Unión y, por ende, para su ordenamiento jurídico. El actual art. 220 TFUE sobre el mantenimiento de relaciones apropiadas con organizaciones internacionales constituye, en este sentido, la base jurídica esencial en los distintos cauces que pueden articularse $^{11}$. Este marco dispositivo, junto con el específico centrado en el ius ad

10 Por ejemplo, en la adopción de posiciones comunes o para ejercer el derecho de voto. Véanse, en relación con las organizaciones internacionales en las que es miembro: Sentencia de 19 de marzo de 1996, FAO, C-25/94, Comisión/Consejo, EU:C:1996:114, apdos. 48 y 49; Dictamen 1/94, de 15 de noviembre de 1994, OMC, EU:C:1994:384, apdo. 108; Sentencia de 5 de diciembre de 2017, Alemania/Consejo (COTIF), C-600/14, EU:C: 2017:935, apdos. 58, 105 y 108; Sentencia de 27 de marzo de 2019, OTIF, Comisión/Alemania, C-620/16, EU:C:2019:256, apdos. 45, 46, 94, 98-100. En el contexto de OOII en las que no es miembro: en el marco de la OIEA, Dictamen 1/78, de 14 de noviembre de 1978, CEEA, EU:C:1978:202, apdo. 36; Dictamen 2/91, de 19 de marzo de 1993, OIT, EU:C:1993:106 apdo. 36 in fine; Sentencia del Tribunal de Justica de 12 de febrero de 2009, OMI, Comisión/Grecia, C-45/07, EU:C:2009:81, apdos. 14, 30 y 31; Sentencia de 20 de abril de 2010, PFO, Comisión/Suecia, C-246/07, EU:C:2010:203, apdos. 71 y 72; Sentencia de 7 de octubre de 2014, OIV, Alemania/Consejo, C-399/12, EU:2014:2258, apdo. 64. Sobre la obligación de cooperar en OOII en las que hay competencias y no membresía (Ramopoulus, 2019: 458). Algunos autores han criticado la interpretación extensa de la obligación de cooperar con el propósito de favorecer la acción de la UE más eficaz en organizaciones internacionales, al evidenciar cierta restricción de libertad de los Estados miembros de la Unión en ámbitos de competencia compartida en el seno de las mismas, como pone de relieve el asunto de la OIV (Govaere, 2014: 229; Fahey, 2019: 656).

11 El art. 220.1 TFUE, incluido en el derecho primario en una versión primigenia desde sus inicios, privilegia a ciertos organismos internacionales - NU en general, a sus órganos y organismos especializados, el Consejo de Europea, la OSCE y la OCDE-. 
tractatum $^{12}$, construido de forma evolutiva en los Tratados originarios, pone de relieve la necesidad que tiene la Unión de otras organizaciones internacionales para alcanzar sus objetivos — a la vez que estas requieren de la UE para desarrollar sus capacidades_- Ello permite la permeabilidad normativa recíproca entre ambas, consecuencia de su interacción creciente.

Los recelos de ciertos Estados a que un sujeto no estatal - como la UE - participe con el estatuto de miembro en estructuras institucionales internacionales ideadas para sujetos estatales continúa existiendo. Ello obstaculiza las reformas de algunos tratados constitutivos de organizaciones internacionales para permitir el acceso de la UE, nominalmente o como Organizaciones

Para el cauce más desarrollado (participación de la Unión), junto a la base del art. 220.1 TFUE, se une(n) la doctrina de los poderes implícitos y/o el recurso a la cláusula de imprevisión (art. 352 TFUE), aportando flexibilidad a la rigidez del principio de atribución de competencias. A las disposiciones ya citadas, en el marco de la PESC el TUE se refiere al CSNU y a las organizaciones internacionales en general en las que no participan todos los Estados miembros (art. 34.2), a NU (art. 42.1) y a la OTAN (art. 42.7). En el TFUE, para favorecer la cooperación de la UE y de sus Estados miembros con «terceros países» y "organizaciones internacionales competentes» en ámbitos materiales diversos, se cita específicamente al Consejo de Europa, tanto en educación y deporte (art. 165.3 TFUE), como en el ámbito de la cultura (art. 167.3 TFUE); a las organizaciones internacionales en general en salud pública (art. 168.3 TFUE), cooperación al desarrollo, mencionando a las NU (arts. 208.2 y 211 TFUE) $y$, en materia de ayuda humanitaria, también citando en particular «a las que forman parte del sistema de las Naciones Unidas» (art. 214.7 TFUE).

12 Véanse los arts. 216 (asumiendo la doctrina AETR sobre competencias implícitas) a 219 TFUE, incluyendo todos ellos alguna mención a organizaciones internacionales. Sentencia del TJCE de 31 de marzo de 1971, AETR, Comisión/Consejo, 22/70, EU:C:1971:32, apdos. 15 y 16. Otras referencias a la conclusión de acuerdos con OOII en el TFUE se encuentran en materias de cooperación al desarrollo (art. 209.2), investigación y desarrollo tecnológico (art. 186), medio ambiente (art. 191.4 TFUE), política comercial común (art. 207.3), cooperación económica, financiera y técnica (art. 212.3), ayuda humanitaria (art. 214.4) y acuerdos de asociación (art. 217). También en los procedimientos para concluir los acuerdos citados (art. 218) y el específico para el régimen monetario o cambiario (art. 219.3). Asimismo, los que permiten que la Unión se adhiera al crear "un marco institucional específico al organizar procedimientos de cooperación» (art. 218.6.a.iii TFUE) o cuando el TFUE se refiere a la posición a adoptar por el Consejo «en nombre de la Unión en un organismo creado por un acuerdo" (art. 218.9 TFUE), por ejemplo, con un estatuto de miembro, si bien la aplicación de dicha disposición, como ha reconocido el TJUE, no se limita a una participación plena (Sentencia de 7 de octubre de 2014, OIV, citada en nota 10). En el marco de la Política Exterior y de Seguridad Común (PESC), el art. 37 TUE. 
de Integración (Económica) Regional (OIER) ${ }^{13}$, o incluso vetando la adopción de resoluciones que oficialicen un estatuto de observador privilegiado para la $\mathrm{UE}^{14}$. El bloqueo a la participación tiene fundamentos de distinta naturaleza (sobrerrepresentación de la UE en la organización internacional o foro u otras cuestiones de naturaleza política o estratégica — como sucede en el Consejo Ártico- $)^{15}$. La adquisición de la condición de miembro de la UE en una organización internacional puede encontrar incluso reticencias provenientes de los propios miembros de la Unión — como ha sido el Reino Unido, junto a otros, en la OMI- ${ }^{16}$. Además, la participación de la UE debe de ser considerada atractiva tanto para la organización internacional en cuestión como para la mayoría de sus Estados, incorporando un valor añadido (potencial económico, seguridad jurídica, mayor peso frente terceros en el ámbito de trabajo de la organización, entre otros). Estos aspectos en el seno de la organización internacional, según los casos, se verán afectados por la retirada del RU de la UE.

El hecho de que la UE no haya conseguido el estatuto de miembro en una organización internacional no significa que su influencia en la misma sea escasa ${ }^{17}$. Es frecuente que la UE, como observadora, haya sorteado deter-

13 En sus inicios denominadas OIER, por el marcado peso del ámbito económico en las mismas. El cambio de denominación a OIR — ya sin el término Económica - aparece, por ejemplo, en la Convención sobre los Derechos de las Personas con Discapacidad de 30 de marzo de 2007, de la que es parte la UE y sus Estados miembros. Véase su art. 44 definiendo la OIR. Klabbers (2019: 26); Wessel y Odermatt (2019: 14). Aunque fue habitual en décadas pasadas, en el inicio del proceso de integración europeo, vinculado a su no reconocimiento como sujeto de derecho internacional, continúa posteriormente, como comprobamos durante la negociación del proyecto de resolución fallida previa a la que permitiera la participación de la UE con un estatuto de observador privilegiado oficial en la labor de las Naciones Unidas en 2011 (A/64/ L67 de 31 de agosto de 2010 y A/RES/65/276, al año siguiente, respectivamente). Barbé Izuel (2012: 46-65); Gstöhl (2009: 385) y Sánchez Ramos (2013: 7). La sobrerrepresentación se ha planteado, por ejemplo, en relación con la presencia europea en la extinta Comisión de Derechos Humanos de Naciones Unidas, sustituida por el Consejo de Derechos Humanos.

16 Junto al Reino Unido, Grecia y los Estados nórdicos mostraron su falta de apoyo en la OMI. Por ejemplo, obstaculizando el proceso de negociación, para impedir el ingreso de la Unión en calidad de miembro

17 Por ejemplo, en la OACI; en la OIT, OMPI y OMS, en las que la UE actúa a modo de dinamizadora (cheerleader) desarrollando en ellas parte de su agenda multilateral, pese a no disfrutar de la condición de miembro (Fahey, 2019: 648). En la OIT, la consolidada posición de la UE se vale de sus Estados miembros, actuando estos como grupo 
minadas carencias derivadas de la falta de membresía a través de sus Estados miembros (y, sobre todo, del que ejerce la Presidencia en el Consejo de la Unión ese semestre). La adopción de convenios en el marco de ciertas organizaciones internacionales por los Estados miembros de la Unión, en nombre de esta, problematiza jurídicamente ciertos aspectos de la retirada del Reino Unido.

Que la UE no sea un sujeto estatal no equivale siempre a encontrar grandes obstáculos para vincularse con estatutos diversos a organizaciones internacionales - como sí sucedía frecuentemente en las primeras décadas del proceso de integración europea-. La práctica institucional muestra que justamente la UE juega con la flexibilidad que le proporciona su singular naturaleza, cuando existe voluntad política por parte de la Unión, sus Estados miembros se encuentran cohesionados a tal fin y la organización en cuestión y sus miembros son receptivos, permitiendo superar las trabas jurídicas de su participación a través de participaciones de facto no reconocidas oficialmente $^{18}$. Una cuestión peliaguda que se plantea es si esta participación de

regional cohesionado, haciendo uso de la palabra en nombre de la Unión y votando consecuentemente en el mismo sentido (Pichot y Delarue, 2019: 104). En el caso de la OMS, pese a su estatuto oficial de mero observador, la UE en la práctica disfruta de una condición especialmente reforzada, a modo de observador privilegiado. De forma que la Unión es invitada como participante pleno a la mayoría de los procesos intergubernamentales que establecen aquellos órganos, actuando con gran flexibilidad en la configuración de las políticas de la OMS (Emmerling, 2019: 122, 123 y 141). La UE cuenta con competencias compartidas y de apoyo en su ámbito competencial de la OMS [arts. 4.2.k y 6.a) TFUE]. Sin ese estatuto de miembro, la UE también desarrolla una creciente influencia en los organismos financieros como el FMI y Banco Mundial, cuando consigue una representación única (Castellarin, 2019: 315). Otros ejemplos se encuentran en relación con las organizaciones internacionales marítimas en el marco del derecho del mar a nivel internacional (como la OMI) y regional (Comisión del Mar Negro) (Cinelli, 2019: 464).

18 Como ocurre con los estatutos de observador privilegiado de la UE de carácter oficioso: Consejo de Derechos Humanos de NU, Comisión Económica para Europa del Consejo Económico y Social de las NU (ECOSOC), OIV —antes de 2017-, en la OACI — que algunos caracterizan como participante pleno diferenciándolo básicamente de la categoría de miembro en la no posesión del derecho de voto (Vaugeois, 2019: 236); o con mayor intensidad aún, como miembro de facto: en la Organización Mundial de Aduanas (OMA), a la espera de la entrada en vigor de la reforma del tratado constitutivo (Schermers y Blokker, 2018: 79), en el Programa de las NU para la Fiscalización Internacional de las Drogas, o en la Comisión para la Conservación del Atún Rojo del Sur (CCARS) desde 2004 como cooperante no miembro, adhiriéndose a la 
facto e intensa de un tercero (como la UE) en una organización internacional o alguno de sus órganos es acorde con el derecho internacional y el propio derecho de la organización inernacional en cuestión cuando esta no modifica su tratado constitutivo para permitir la adhesión de la UE como miembro (Odermatt y Wessel, 2019: 668-671).

La UE evoluciona como sujeto normativo y actor global, que se consolida paulatinamente, impulsa y protege ad extra — con resultados variopintoslos principios y valores que forman parte de su ordenamiento, y que comparte con sus Estados miembros, valiéndose de las organizaciones internacionales en las que participa ${ }^{19}$. La UE se encuentra involucrada activamente en la creación de normas del derecho internacional, siendo una opción consciente. Dicha labor se encuentra en el propio ADN de la UE, al constituir ella misma per se un ejemplo representativo del multilateralismo (eficaz), que es un elemento esencial de su acción exterior ${ }^{20}$. Por ello, como «comunidad de derecho» que $\mathrm{es}^{21}$, la UE decide e influye de acuerdo con sus postulados y normativa en los desarrollos jurídicos de numerosas organizaciones, con mayor contundencia en los casos en los que adopta posiciones comunes consensuadas con sus Estados miembros — si la participación en la organización internacional es mixta o incluso si participan ellos únicamente y la UE como observadora, con mayor o menor intensidad dependiendo de las competencias de la Unión

Comisión Ampliada en calidad de miembro en 2015. En la OCDE, pese a la resistencia de terceros Estados para que la UE obtuviera la condición de miembro, actualmente mantiene un estatuto de "participante en los trabajos» que la sitúa como observador extremadamente privilegiado e incluso miembro de facto (Vlastou-Dimopoulou, 2019: 336).

19 Véanse los arts. 2, 3.5 y 21.1 TUE. Como esta última disposición indica en su párrafo segundo: «La UE procurará desarrollar relaciones y crear asociaciones con los terceros países y con las organizaciones internacionales, regionales o mundiales que compartan los principios mencionados en el párrafo primero. Propiciará soluciones multilaterales a los problemas comunes, en particular en el marco de las Naciones Unidas» (cursiva añadida). La destacada NU, que aparece como la organización internacional más citada en los Tratados que conforman el derecho primario (Wouters y Chané: 2016: 324).

20 González Alonso (2011: 15); Koops (2011: 35). Identificando una vía unilateral o bilateral de la UE en la salvaguarda de sus intereses, más propia de un sujeto estatal, Amtenbrink y Kochenov (2014: 358).

21 Sentencia del Tribunal de Justicia de 23 de abril de 1986, asunto 294/83, Les Verts, EU:C:1986:166, apdo. 23 y Sentencia del Tribunal de Justicia de 25 de julio de 2002, C-50/00 P, Unión de Pequeños Agricultores, EU:C:2002:462, apdo. 38. 
en la materia tratada- ${ }^{22}$. Ello con independencia de que en la mayoría de los casos los actos adoptados en las organizaciones carezcan de fuerza jurídica vinculante. La falta de obligatoriedad no es óbice para que el soft law emanado de las OOII tenga un impacto en el ordenamiento jurídico de la UE, así como en el ordenamiento jurídico internacional. La interacción normativa UE y organizaciones internacionales se produce en ambos sentidos (Costa y Jørgensen, 2012).

En definitiva, la valoración que hacemos en el presente, teniendo en cuenta el contexto general relativo a la participación de la UE en organizaciones internacionales — si partimos de los estudios realizados en esta materia a finales del siglo $\mathrm{xx}$ y en los primeros años del siglo $\mathrm{XxI}^{23}$ - muestra que el estado actual de la Unión es positivo y su influencia a nivel jurídico, político y económico en, y respecto a, numerosas organizaciones internacionales resulta actualmente mayor que nunca. Ello sitúa a la Unión en un buen punto de partida para encauzar y gestionar los distintos efectos que la retirada del RU está produciendo, y que pasamos a analizar en el epígrafe siguiente.

\section{EL IMPACTO JURÍDICO-POLÍTICO DEL BREXIT}

El Brexit va a incidir en las relaciones de la UE y del Reino Unido en organizaciones internacionales de forma variable, en distintos ámbitos materiales y en relación con muchas de esas organizaciones dependiendo de la participación que desarrolle la UE y el RU en cada una de ellas, de acuerdo con sus singularidades. La casuística que se plantea es, por ello, extremadamente rica. Teniendo en cuenta este contexto, realizamos una aproximación al objeto de estudio distinguiendo dos fases temporales: la primera, durante el periodo

22 El TJUE interpretó de forma extensiva que la UE sí que está facultada para determinar la posición que debe adoptarse en su nombre en lo relativo a las recomendaciones de la OIV objeto del caso, debido a la «incidencia directa que tienen sobre el acervo de la Unión en dicho ámbito». Esto es, los actos (recomendaciones) del organismo (OIV) «surtan efectos jurídicos» en el derecho de la Unión (en el sentido del art. 218.9 TFUE). Véase la Sentencia de 7 de octubre de 2014, OIV, citada en nota 10, apdos. 64, 56 y 61. Otro ejemplo, que muestra la influencia de la Unión, en un ámbito bien diferente, es el de la promoción de los derechos humanos. En este, aunque de forma más liviana, la acción de la UE también incide en las actividades de la Asamblea General de las NU (tercera comisión) o en el Consejo de Derechos Humanos (Wouters y Meuwissen, 2013: 7; Pérez Bernárdez, 2016: 368-370).

23 Frid (1995), Remiro Brotóns (1986), Roldán Barbero (1998) y Santos Vara (2002), entre otros. 
transitorio de 2020, teniendo en cuenta las normas recogidas en el Acuerdo de Retirada en vigor ${ }^{24}$. En la segunda fase, que se desarrolla durante el periodo posterior al transitorio a partir de 2021, examinamos los posibles escenarios que se presentan dependiendo del resultado de las negociaciones tendentes a conseguir un acuerdo de partenariado UE-RU post-Brexit, así como la normativa previsiblemente aplicable en ambos supuestos, partiendo de las propuestas unilaterales presentadas en febrero y marzo de 2020 por las partes y desarrolladas en las sucesivas rondas negociadoras, lideradas por los representantes de la UE y del RU, Michel Barnier y David Frost, respectivamente. Con independencia de la existencia o no de dicho acuerdo de partenariado, analizamos distintas categorías atendiendo a la participación de la UE y del Reino Unido en la organización internacional en cuestión. Ello nos permite extraer algunas pautas comunes en cada una de dichas categorías: $i$. en calidad de miembro, conjuntamente para la UE y el RU, ii. en la situación previa mencionada, pero con la singularidad de participar el RU únicamente en relación con sus territorios dependientes, iii. participando de forma exclusiva la UE en la organización internacional en cuestión y, finalmente, $i v$. la UE con la condición de observadora. Todo ello con el examen específico de algún caso particularmente ilustrativo.

\section{EN EL PERIODO TRANSITORIO}

Comencemos con el análisis del Acuerdo de Retirada en lo concerniente a las relaciones de la UE con organizaciones internacionales (1.1), continuando con la exposición de uno de los numerosos ejemplos de planes de contingencia específicos adoptados por parte de la UE, en este caso, ante una organización regional de ordenación pesquera (OROP), que muestra la relación constructiva entre la partes (1.2).

\subsection{El Acuerdo de Retirada}

Desde el 1 de febrero hasta el 31 de diciembre de 2020, el Acuerdo de Retirada ha establecido un periodo transitorio en que aplica al Reino Unido el derecho de la Unión (art. 127.1), con los mismos efectos jurídicos que

24 Acuerdo sobre la Retirada del Reino Unido de Gran Bretaña e Irlanda del Norte de la Unión Europea y de la Comunidad Europea de la Energía Atómica (AR, en adelante), citado supra en nota 3. Cuarta Parte sobre Transición (arts. 127 a 132). 
"produce en la Unión y en sus Estados miembros» ${ }^{25}$. En sus disposiciones específicas relativas a la acción exterior de la Unión — condensadas en el art. 129- se menciona expresamente la obligatoriedad del Reino Unido de quedar vinculado por las obligaciones que se deriven de los acuerdos internacionales celebrados por la Unión Europea, por los Estados miembros que actúen en nombre de esta, o por la Unión y sus Estados miembros conjuntamente ${ }^{26}$. Se incluye, por tanto, una obligación amplia para el RU en relación con sus compromisos dentro de la Unión, incluso en aquellos supuestos en los que por distintos motivos no es esta la que participa como sujeto expresamente en el acuerdo, sino los Estados miembros en su nombre ${ }^{27}$.

Como medida de salvaguarda el Acuerdo de Retirada contempla la restricción de actuación por parte de los representantes del RU en los trabajos de las organizaciones internacionales (art. 129.2 AR), lo cual es lógico, teniendo en cuenta que los intereses británicos en dichos organismos podrían colisionar con la posición de la Unión —avistando el futuro de participación independiente-, debiendo proteger la Unión y sus Estados miembros sus derechos. Por ello se incluye expresamente la aplicación del principio de cooperación leal, debiendo el Reino Unido de abstenerse de acciones que pudieran ir en detrimento de los intereses de la UE en organizaciones internacionales en las que el RU «sea parte por derecho propio» (arts. 129.3 AR). Pese a la tensión competencial existente entre la UE y el Reino Unido en el contexto de ciertas organizaciones internacionales, este principio se había

25 Un derecho de la Unión que se interpreta y aplica según «los mismos métodos y principios generales que los aplicables dentro de la Unión» (art. 127.2 Acuerdo de Retirada).

26 Esta última modalidad es la referida a los acuerdos mixtos, con competencias tanto de la UE como de sus Estados. Constituyen menos de un tercio de los concluidos por la UE (Miller, 2017). Las complejidades que supone la salida del RU en la adaptación de los acuerdos mixtos que ha concluido, por la oportunidad que se presenta en su renegociación para las partes, ha sido puesta de relieve por algún autor aludiendo a que "Brexit may thus open up Pandora's Box» (Van der Loo y Blockmans, 2016). Los acuerdos concluidos en el marco de organizaciones internacionales en los que la UE actúa a través de sus Estados miembros se celebran, por ejemplo, en aquellas en las que la UE, pese a tener importantes competencias, no posee el estatuto de miembro, como en la OIV, OMI u OACI. El Acuerdo de Retirada confirma desde el inicio esta laxa y necesaria interpretación para salvaguardar los intereses de la UE, pese a no ser parte (o miembro de la organización internacional, por extensión) del acuerdo internacional [art. 2.a) iv AR]. Asimismo, se señala la obligación de la UE de notificar a las demás partes en los acuerdos que el RU «debe ser tratado como Estado miembro a efectos de estos acuerdos» durante el periodo transitorio (nota al pie del art. 129.1). 
respetado adecuadamente durante la fase previa a la retirada británica, como tras ella durante el periodo transitorio ${ }^{28}$. Junto a la participación del RU por propio derecho - como miembro de la organización internacional- en el marco de sus competencias (art. 129.2 a), también podrá acudir porque la Unión excepcionalmente invite al RU a «asistir como parte de la delegación de la Unión» a reuniones de estos organismos, al considerar esta que la presencia en las mismas del RU es «necesaria y redunda en interés de la Unión», por ejemplo para la aplicación efectiva de los acuerdos y siempre que se permita en los mismos la participación de los Estados (art.129.2, b) AR). Este supuesto está pensado para aquellas organizaciones internacionales en las que participa exclusivamente la UE sin sus Estados miembros. Por ejemplo, en el contexto relativo a la preparación de la adhesión futura del RU a organizaciones regionales de ordenación pesquera (art. 130.3), conciliando los intereses de la UE y de sus Estados miembros, por un lado, y los del Reino Unido en lo que se refiere al régimen específico relativo a las posibilidades de pesca ${ }^{29}$.

En otro ámbito material bien distinto y también sensible, potencialmente durante este ínterin transitorio, la UE y el RU podrían haber alcanzado

28 Tanto por parte de el RU con una capacidad limitada de exploración y negociación de acuerdos internacionales con terceros - Estados y organizaciones internacionalescomo de la UE, permitiendo cierto grado de libertad y colaboración para ir preparando jurídicamente su retirada (Lazowski y Wessel, 2016). Fuera del contexto de las organizaciones internacionales, sí que han surgido controversias relacionadas con la interpretación y aplicación del Acuerdo de Retirada. La aprobación el 9 de septiembre de 2020 de un proyecto de Ley sobre el Mercado Interior del Reino Unido en el Parlamento británico introduce cláusulas que vulnerarían a priori el Acuerdo de Retirada en vigor en relación con las declaraciones aduanares y ayudas de Estado vinculadas a Irlanda del Norte, en concreto al Protocolo sobre Irlanda e Irlanda del Norte. La posición británica mantiene que la aprobación de esta ley no generaría incumplimiento al tratarse de meros tecnicismos que evitan lagunas jurídicas. La Comisión Europea ha iniciado un procedimiento de infracción contra el RU remitiendo una carta de emplazamiento a este Estado. Comunicado de prensa de 1 de octubre de 2020. El atrevimiento británico a la hora de legislar interpretando con falta de rigor un acuerdo vinculante en un momento especialmente sensible añade una dificultad suplementaria al estadio actual de negociación, erosionado la credibilidad británica.

29 Teniendo en cuenta las competencias exclusivas de la UE en la conservación de recursos biológicos marinos dentro de la política pesquera común [art. 3.1, d) TFUE]. Se prevé la consulta al RU sobre esta materia, que presente observaciones (art. 130.1 y. 2 AR), así como la invitación excepcional por parte de la Unión a formar parte de su delegación para asistir «a las consultas y negociaciones» sobre la pesca, con vistas a preparar la participación del RU en los foros internacionales pertinentes (art. 130.3 AR). 
un acuerdo sobre la PESC y la Política Común de Seguridad y Defensa $(\mathrm{PCSD})^{30}$. Dicho entendimiento no se ha conseguido ni traducido en un acuerdo, debido en gran medida, a las expectativas diferentes de las partes. Las excepcionales circunstancias ocasionadas por la pandemia no han contribuido desde luego a encontrar espacios de negociación que llevaran a avanzar siquiera parcialmente a través de convenios en ámbitos materiales concretos la futura regulación de sus relaciones — tampoco en la PESC—. El Gobierno británico - y más acusadamente con el primer ministro Boris Johnson- ha descartado solicitar una prórroga del periodo transitorio (art. 132) que le permitiera contar con un tiempo suplementario y, así, articular la negociación del acuerdo de partenariado UE-RU post-Brexit de una manera más pausada y ordenada ${ }^{31}$.

\subsection{Un plan de contingencia}

Detengámonos a analizar algunos efectos del Brexit ya producidos en una organización regional de ordenación pesquera, la Comisión de Pesquerías del Atlántico Nordeste (CPANE o NEAFC, por sus siglas en inglés), en la que participa la UE como miembro de forma exclusiva, sin gozar el Reino Unido de un estatuto de miembro - tampoco en relación con sus territorios dependientes, como sí ocurre con Dinamarca-. El Reino Unido solicitó su adhesión de forma temprana como miembro el 8 de enero de 2019 a esta OROP, en previsión de un Brexit sin acuerdo. La UE adoptó con premura un plan de contingencia, teniendo ya preparada su posición apoyando la solicitud de adhesión del RU a la convención constitutiva de la CPANE, mediante una propuesta de decisión del Consejo ${ }^{32}$, habida cuenta de los

30 Ello hubiera llevado a dejar de aplicar al Reino Unido el capítulo 2 del título V del TUE (sobre las disposiciones específicas de la PESC, conforme al art. 127.2 AR). Entre tanto, el RU seguiría contribuyendo a la financiación de la Agencia Europea de Defensa, el Instituto de Estudios de Seguridad y el Centro de Satélites de la UE, así como asumiendo los costes de las operaciones de la PCSD hasta el 21 de diciembre de 2020 (art. 156 AR).

31 Dicha prórroga debería haberse solicitado antes del 1 de julio de 2020, permitiendo extender más allá del 31 de diciembre de 2020 y hasta un máximo de dos años para continuar la negociación —en caso de aceptación por parte de la UE-.

32 La base jurídica de este acto que contiene la posición favorable a la adhesión en nombre de la UE han sido los arts. 218.9 y 43.2 del TFUE. Cfr. Comisión Europea, Propuesta de Decisión del Consejo relativa a la posición que debe adoptarse, en nombre de la Unión Europea, en el marco del Convenio sobre la futura cooperación multilateral en los caladeros del Atlántico Nororiental por lo que refiere a la solicitud 
intereses coincidentes de la Unión, sus Estados miembros y del Reino Unido. Efectivamente, el Convenio CPANE se venía aplicando a este Estado al ser la UE parte de dicho Convenio y, del interés legítimo de pesca — sostenible— del RU en la zona del Convenio, una vez dejara de formar parte de la UE. Dicho plan de contingencia no ha sido necesario aplicarlo - hasta el momento- al establecerse el ya referido periodo transitorio de aplicación del derecho de la UE al RU hasta finales de $2020^{33}$.

Podemos reflexionar aquí si esta actividad preparatoria realizada por la UE y el RU con el objeto de salvaguardar sus intereses mutuos en el marco de la CPANE será útil para la incorporación inminente del RU a esta organización -independientemente de que haya o no acuerdo regulador de sus relaciones mutuas en esta materia - y si es extensible a otras en casos análogos. A la primera cuestión sobre su utilidad nuestra respuesta es positiva, ya que creemos que estos trabajos y negociaciones son puntos de convergencia entre las partes que facilitan un clima de entendimiento entre la UE y el RU de cara al futuro. De manera que aquella labor pueda aprovecharse teniendo en cuenta la adhesión próxima del RU a ese organismo — pensemos en cómo facilitará los ajustes a realizar en la organización internacional relativos a los derechos y obligaciones derivados de la condición de miembro-. Ahora bien, en relación con la segunda cuestión, las diferentes situaciones en las OROP plantean ya dificultades para aplicar el mismo procedimiento a otros supuestos, al constituir cada una de ellas un universo individual y concreto. A la vista está que los intereses pesqueros del RU ante organizaciones internacionales y en relación con el uso de sus aguas (como la zona económica exclusiva) por barcos comunitarios ha sido uno de los aspectos más sensibles y complejos de la negociación con la $\mathrm{UE}^{34}$.

de adhesión del Reino Unido a dicho Convenio, Bruselas, 12.3.2019 COM(2019) 140 final. Véase en relación con la CPANE (art. 1, a) de la Decisión de Ejecución (UE) 2020/1305 del Consejo de 18 de septiembre de 2020 por la que se autoriza al Reino Unido a manifestar su consentimiento, en nombre propio, en obligarse por determinados acuerdos internacionales que deban aplicarse durante el periodo transitorio en el ámbito de la política pesquera común de la Unión, (DO L 305, 21.9.2020, pp. 27-29).

33 Ibid. Propuesta de Decisión del Consejo, punto 5, p. 6. Véase también en relación con la OPANO, CICAA, CAOI y OCSAN (art. 1, b) a e) de la Decisión de Ejecución — citada en la nota anterior - en el marco del art. 129.4 AR.

34 La negociación de un acuerdo de pesca como instrumento capital que regule el acceso a las aguas entre la UE y el Reino Unido, así como las cuestiones relacionadas (posibilidades de pesca y conservación y gestión de los recursos pesqueros) «no resultará sencilla» (Sobrino Heredia, 2020: 297). 


\section{EN EL PERIODO POSTERIOR AL TRANSITORIO}

Como fase más relevante a partir de 2021, se presentan mayores incertidumbres.

\subsection{Escenarios y normativa}

Para este segundo periodo se plantean en principio dos posibilidades: primero, que haya finalmente un acuerdo (de partenariado) que regule las relaciones entre la UE y el RU post-Brexit, esto es, un escenario pactado y ordenado con una vocación potencial de mantenerse en el tiempo, que aporte una mayor seguridad jurídica — con independencia de que rste pueda modificarse posteriormente de acuerdo con las reglas establecidas en el mismo-. Segundo, que no se consiga concluir este acuerdo post-Brexit, produciéndose una desconexión abrupta de sus relaciones mutuas, al dejar de aplicarse el derecho de la Unión al RU a partir del 1 de enero de $2021^{35}$.

En el primer escenario, en el caso de acordar las partes un acuerdo de partenariado UE-RU post-Brexit, este podrá tener la forma de un único instrumento - o varios, como parece más probable, atendiendo a distintos ámbitos materiales, como el comercial y el pesquero-. Este Acuerdo, para la UE, quedaría integrado en su derecho, constituyendo la base jurídica principal de las relaciones entre las partes. Las disposiciones de este acuerdo marcarán las directrices de los ajustes que la UE y el RU tengan que realizar en las organizaciones internacionales.

En el segundo escenario, en el caso de no contar con acuerdo post-Brexit, aparentemente se produciría un cierto vacío jurídico inmediatamente después de la expiración de la fase transitoria en la que se aplica el derecho de la Unión - a partir de 2021 - . No obstante, aquel vacío no sería total, ya que contamos con la aplicación supletoria del derecho internacional en ausencia de reglas particulares entre las partes ${ }^{36}$. No recurriríamos al fundamento básico convencional que supone el acuerdo de relación UE-RU post-Brexit, pudiendo este celebrarse con posterioridad a enero de 2021 — si ambas partes preservan el espíritu negociador necesario_ - pero entrando ya en una fase de desconexión

35 ¿Serán las partes capaces de idear una tercera vía imaginativa jurídicamente viable ante esta situación? No nos resultaría descabellado, ante las consecuencias negativas que el escenario segundo generaría y el estado de bloqueo de las negociaciones a menos de dos meses de llegar a la expiración del periodo transitorio.

36 Wessel (2019: 441). En el ámbito de la política pesquera común, finalizado el periodo transitorio y sin acuerdo UE-RU post-Brexit, será de aplicación del derecho internacional público (Sobrino Heredia, 2020: 294). 
desordenada hasta la aplicación de este hipotético acuerdo. Tampoco sería descartable que algunas partes de ese acuerdo post-Brexit o la totalidad del mismo se aplicasen provisionalmente para evitar la inseguridad jurídica.

En relación con los sujetos de derecho internacional afectados por la participación de la UE en organizaciones internacionales, serían de aplicación, dependiendo de la actividad, el derecho de la $\mathrm{UE}^{37}$, las reglas de la organización internacional en cuestión —esto es, el propio derecho de la organización internacional, con su tratado constitutivo como instrumento principal— ${ }^{38}$ $y$, de forma subsidiaria, las normas generales del ordenamiento jurídico internacional (convenciones, costumbres y principios generales del derecho) ${ }^{39}$ que

37 Pensemos, en general, en los más de mil acuerdos internacionales bilaterales o multilaterales concluidos por la UE con terceros sobre muy diversas materias que se integran en el derecho de la Unión. A fecha de agosto de 2020 se computan 1266 en total, 982 bilaterales y 284 multilaterales, según la Treaties Office Database de la UE. Como ejemplos más específicos relativos a la vida institucional de la UE en organizaciones internacionales, se encuentran, entre otros, la fijación una declaración competencial entre la Unión y sus Estados miembros de acuerdo con el orden del día de las reuniones celebradas en los órganos de la organización, facilitando identificar al sujeto - la UE o sus Estados participantes - al que corresponde el uso de la palabra y el derecho de voto o para adoptar una posición única que pueda defenderse en nombre de la Unión en el seno de la organización.

38 Además de las decisiones y resoluciones adoptadas de conformidad con el acuerdo constitutivo y la práctica establecida, que también conforman las reglas de la organizaciones internacionales (art. 2.1.j de la Convención de Viena de 1986 sobre el derecho de los Tratados celebrados entre Estados y organizaciones internacionales o entre estas últimas abierta a la firma el 21 de marzo de 1986). Ejemplos de la aplicación de estas reglas serían la adopción de resoluciones con el objeto de fijar la cuota presupuestaria de la organización internacional, los derechos de uso de la palabra y de voto. Estas actividades se verán afectadas, con variaciones según la organización internacional, por la retirada del Reino Unido de la Unión.

39 Un ejemplo sería la Convención de Viena de 1986 citada en la nota previa que, pese a no haber entrado aún en vigor, posee disposiciones que son invocadas a modo de costumbre internacional. Sus reglas son muy similares a las de la Convención de Viena de 23 de mayo de 1969 para los Estados, que goza de una aceptación universal. Véanse, inter alia, los arts. 54 y 56 la Convención de Viena de 1969 en relación con la retirada. Otro ejemplo sería el Convenio sobre representación de los Estados en sus relaciones con las organizaciones de carácter universal, firmado en Viena el 14 de marzo de 1975, que tampoco se encuentra en vigor, pero que mantiene un núcleo dispositivo que podría tenerse en consideración. Sobre la aplicación a los procesos de retirada del derecho de los tratados, la costumbre internacional y el derecho de las organizaciones internacionales véase Brölmann et al. (2018: 247-251). 
regulan, inter alia, las relaciones entre Estados y otros sujetos de derecho, como las organizaciones internacionales.

\subsection{Hacia un acuerdo de partenariado post-Brexit}

La UE publicó un Proyecto de Acuerdo para la Relación Futura con el Reino Unido que le remitió a este Estado el 18 de marzo de $2020^{40}$, tras las pertinentes consultas con el Parlamento Europeo y el Consejo. Un extenso documento de 440 páginas que aborda todos los ámbitos materiales de la negociación. El objeto del mismo fue servir como instrumento en las negociaciones, traduciendo las líneas básicas negociadoras aprobadas por los Estados miembros a un texto jurídico, en línea con la Declaración Política Revisada en la que se expone el marco de las relaciones futuras entre la UE y el RU de octubre de $2019^{41}$. Llama la atención en dicho proyecto de acuerdo el alto compromiso con el multilateralismo institucional del que parte la UE en su negociación, así como la mención a numerosas organizaciones internacionales, dependiendo del ámbito de cooperación tratado ${ }^{42}$. Contrasta claramente con la versión británica de este documento (Our approach to the Future Relationship with the EU, de febrero de 2020), mucho más escueto y

40 Draft text of the Agreement on the New Partnership with the United Kingdom, European Commission, Task Force for Relations with the United Kingdom, UKTF (2020) 14, presented to the Council Working Party on the United Kingdom on Friday 13 March 2020. Con una breve adenda publicada en agosto sobre objetos culturales.

41 Declaración Política de octubre de 2019, Task Force for the Preparation and Conduct of the Negotiations with the United Kingdom under Article 50 TEU. Esta recoge alusiones a distintas organizaciones internacionales (NU, OTAN, OMC, OMPI y OIEA, entre otras) en el marco material específico en el que vincula la previsible acción del RU y de la UE; compromisos de cooperar estrechamente con organizaciones internacionales y otros foros, incluyendo el mantenimiento posiciones comunes, en su caso (párr. 96).

42 Por ejemplo, sobre la promoción de valores comunes en foros internacionales (art. COMPROV.4); la cooperación global en asuntos de interés compartido, promoviendo soluciones multilaterales a problemas comunes [art. COMPROV. 11(1)]; estableciendo como medios a tal fin, el diálogo efectivo y la coordinación de posiciones, cuando sea posible, en organizaciones y foros multilaterales en los que participen el RU y la UE [art. COMPROV. 11(2)]. Las referencias explícitas a organizaciones internacionales son muy numerosas, inter alia, OMC, FMI, Banco Mundial, OMA, OACI, OIT, OMI, UNCTAD, OMPI, OIEA, OCDE, Organizaciones regionales de ordenación pesquera, Consejo de Europa, FAO, Codex Alimentarius, NU y algunos de sus órganos, como el CSNU. 
con escasas referencias a organizaciones internacionales ${ }^{43}$. De hecho, el RU se limita a proponer para su futura relación con la UE de forma más aséptica ciertos modelos de acuerdos utilizados por la UE con terceros Estados. Por ejemplo, en pesquerías el modelo UE/Noruega ${ }^{44}$, en materia comercial el CETA - acuerdo integral de economía y comercio- concluido con Canadát5, el de partenariado económico UE/Japón o de libre comercio con Corea del Sur, que contemplan una relación variable y menos integradora con la que el RU desea tratar a la UE en la futura relación.

Sobre esta base, el acuerdo post-Brexit se ha negociado con intensidad, dificultado durante unos meses por la imposibilidad de mantener reuniones presenciales por la pandemia. A lo que se ha unido la puesta en jaque por parte del RU, antes comentada, de ciertos compromisos jurídicos vinculantes del Acuerdo de Retirada ${ }^{46}$. Justamente es el ámbito relativo a la pesca, con una solución justa y duradera para los pesqueros europeos, el que más está costando desbloquear en la negociación en su recta final, con una incidencia relevante en la participación de la UE en ciertas organizaciones internacionales, como en las $\mathrm{OROP}^{47}$. Los aspectos procedimentales vinculados a la

43 Policy paper Our approach to the Future Relationship with the EU. The UK's approach to negotiations with the European Union, 27 February 2020, last updated 19 May 2020, presentado al Parlamento por el primer ministro por orden de su majestad. Se mencionan expresamente: OMC, OCDE, OMA, OMPI, OMI, OIT, FAO, Codex Alimentarius o el CSNU.

44 Este modelo pertenece a la fórmula de acuerdos de pesca denominados de reciprocidad o septentrionales que vinculan a la UE con otros países europeos que no son miembros. Unos acuerdos que ya preveía Sobrino Heredia en 2018 como el «espejo en el que parecen mirarse las futuras relaciones pesqueras post-brexit entre la UE y el Reino Unido» (2018: 841).

45 Ya un estadio muy avanzado de las negociaciones, a dos meses de finalizar el periodo transitorio, el modelo de acuerdo comercial UE-RU que propone el primer ministro Johnson no es ya el canadiense — con la práctica totalidad de exoneración de aranceles - sino el modelo australiano, en el que las relaciones económicas se regulan mediante un acuerdo marco UE-Australia firmado en 2008 «que se limita a favorecer el comercio de productos industriales entre ambos socios y elimina algunos obstáculos técnicos al comercio de servicios y las inversiones». El modelo australiano es mucho más limitado y se basa en principios más simples de libre comercio internacional. Sobre una comparativa entre ambos modelos véase Hinojosa Martínez (2020: 9-12). Véase nota 28.

47 Así, durante la quinta ronda negociadora celebrada a finales de julio de 2020 los principales obstáculos, según ha destacado el negociador principal de la UE, se referían, primero, a la falta de acuerdo sobre el denominado level playing field. La novena ronda arrastra como ámbitos críticos en los que no se consigue avanzar: las ayudas de 
celebración del acuerdo de partenariado evidencian la falta de tiempo para conseguir su aplicación para inicios de 2021, por lo que se están buscado fórmulas que, llegado el caso, permitan el despliegue de sus efectos a tiempo —como su aplicación provisional-.

\subsection{Categorías de participación de la UE y del RU en organizaciones internacionales}

Si bien es cierto que cada organización internacional construye su propio ordenamiento individual condicionado por factores de índole diversa y que la determinación de los posibles efectos jurídicos y políticos derivados del Brexit que determinen las futuras relaciones de la UE y del RU en organizaciones internacionales precisa de un examen singularizado - lo cual requeriría ser objeto de otros trabajos - ${ }^{48}$, nuestro objetivo es extraer algunas pautas de carácter general, teniendo en cuenta los distintos tipos de participación de la UE y del RU en las organizaciones internacionales. Al hilo de este análisis, el examen más detenido de alguna organización internacional nos permite aproximarnos a esta heterogénea realidad. En este estudio, nos centraremos en la situación que se producirá una vez transcurrido el periodo transitorio mencionado y con independencia de lo que el posible Acuerdo de Relación UE-RU post-Brexit establezca en estas materias.

\section{i) Participación conjunta en calidad de miembro de la UE y de sus Estados} miembros (incluido el $R U$ antes de su retirada de la Unión) en una organización internacional.

En este supuesto, existen ejemplos abundantes ${ }^{49}$. La condición de miembro tanto de la UE como del Reino Unido se mantendría en la organización

Estado y el acuerdo pesquero. La Declaración Política Revisada de octubre de 2019 ilusamente incluía el ambicioso objetivo de tener los acuerdos pesqueros ya ratificados por parte de la UE y del RU para julio de 2020 (párr. 74).

Sobre las rondas negociadoras celebradas entre la UE y el RU, véanse los documentos sobre sus resultados, fechas y programas, desde la primera a inicios de marzo de 2020 y la novena, celebrada entre el 29 de septiembre y el 2 de octubre de 2020, disponibles en: https://bit.ly/3lG2fY1.

48 Sobre la necesidad un análisis específico caso por caso véase Dougan (2018: 96).

49 Esta situación de participación conjunta en calidad de miembro de la UE y de todos o algunos de sus Estados se da en numerosas organizaciones internacionales. Entre otros, en la FAO, Organización Mundial del Comercio (OMC), Autoridad Internacional de los Fondos Marinos (AIFM), EUROCONTROL, Organización Mundial de Aduanas (OMA), la Comisión para la Conservación de los Recursos Marinos Vivos 
internacional en cuestión. Desde su retirada de la UE, el RU se ocuparía de ejercer plenamente y de forma autónoma sus derechos (presencia, voz y voto) y cumplir con sus obligaciones institucionales (por ejemplo, contribución al presupuesto) en su calidad de Estado miembro en la organización internacional. De esta forma la UE dejaría de actuar en nombre del RU, en los ámbitos materiales de la organización en los que la UE fuera competente, no gestionando las competencias exclusivas o compartidas con aquel. En este contexto, la Comisión Europea, en nombre de la UE, dejaría de defender el interés del $\mathrm{RU}^{50}$. El RU no acudiría a las reuniones de coordinación con la UE y sus Estados miembros con el fin de consensuar posiciones comunes para defender (o votar) en los órganos de la organización internacional - aunque pudiera hacerlo excepcionalmente en calidad de tercero, si es invitado, como hacen otros Estados europeos-. El RU reforzaría su representación permanente ante la organización internacional en cuestión, ya que deja de utilizar la delegación de la UE acreditada en aquella que le servía de apoyo. Estos cambios tendrán incidencias en la organización internacional - dependiendo de la misma - y posiblemente en el resto de los Estados (por ejemplo, excluyendo del orden del día de las reuniones aquellas informaciones suplementarias sobre declaraciones competenciales de la UE/Estados miembros en relación con los puntos a tratar o las relativas al ajuste en el voto o contribuciones presupuestarias en el ejercicio correspondiente entre los miembros de la organización en relación con el Reino Unido). Fijémonos con más detenimiento, en particular: en la Organización Internacional del Cacao (a), por la reiterada participación de la UE en este tipo de organizaciones que gestionan productos básicos, así como por la intensidad de la actividad de la Unión en aquella en comparación con la de sus Estados miembros; en la FAO (b), por constituir el primer organismo especializado de las Naciones Unidas en el que la UE se adhirió como miembro y una organización de referencia que permite exponer con mayor claridad los efectos jurídicos que plantea el Brexit, finalmente, de manera concisa, en la OMC (c) por su relevancia institucional

Antárticos (CCRMVA), la Comisión para la Protección del Medio Marino del Atlántico Nordeste (OSPAR), la Agencia Internacional de Energía Renovables (IRENA) y la Organización Intergubernamental para los Transportes Internacionales por Ferrocarril (OTIF). También en distintos organismos sobre productos básicos (como el que se ocupa del cacao, del café, de maderas tropicales, o los grupos internacionales de estudio del estaño, del cobre, del níquel, del zinc o del yute).

50 En este sentido, Lazowski y Wessel (2016) son claros al señalar que: «Leaving the EU implies that the international legal position of the UK will have to be reset and certain dimensions of its statehood will have to be reactivated", no pudiendo contar, a partir de entonces, con la experticia de la UE. 
como eje central de la regulación del comercio internacional, en la que se vislumbra una relación constructiva entre la UE y el RU pero compleja de articular, pese a la similitud de objetivos que mantienen sobre cómo hacer frente a los desafíos que se plantean en aquella organización internacional.

\section{a) El caso de la Organización Internacional del Cacao}

Como sucede con cada organización internacional, también las que gestionan convenios reguladores sobre productos básicos poseen singularidades de acuerdo con sus propias reglas. Los actuales miembros de la Organización Internacional del Cacao (OIC) representan el $85 \%$ de la producción mundial y el $60 \%$ del cacao que se consume ${ }^{51}$. El Reino Unido se encuentra entre estos últimos como Estado importador —al igual que los Estados miembros de la UE, junto a Suiza y la Federación Rusa-. Esta organización dedicada a la regulación del cacao se encuentra dentro del conjunto de organizaciones internacionales en las que participan tanto la UE como sus Estados miembros, pero con un protagonismo evidente de la UE. Así, antes de la retirada del RU de la UE, esta desarrollaba la práctica totalidad de la actividad de sus Estados miembros en la OIC, incluyendo al Reino Unido.

El séptimo Convenio Internacional del Cacao, de 2010, firmado por la $\mathrm{UE}^{52}$, recoge referencias expresas a la «Unión Europea y a toda organización intergubernamental $[\ldots]$ que tenga responsabilidades comparables en lo que respecta a la negociación, celebración e implementación de convenios internacionales, en particular de convenios sobre productos básicos» (arts. 2.9 y 4.5, respectivamente, convenio de 2010 citado). Como consecuencia de la retirada del RU de la UE, la OIC debe realizar acomodos (en materia de

51 La OIC fue establecida en 1973 — con sede primero en Londres y desde 2017 en Abiyán (Costa de Marfil), como principal Estado exportador de cacao-. Tiene como objetivo establecer un mercado transparente que englobe tanto a los productores como a consumidores (art. 1 sobre sus objetivos) del Convenio Internacional del Cacao de 2010, publicado en DO L 259, de 4 de octubre de 2011, pp. 8-30.

52 Ibid. Decisión del Consejo de 17 de mayo de 2011 relativa a la firma, en nombre de la UE del Convenio Internacional del Cacao y su aplicación provisional en 2010 (DO L 259, de 4 de octubre de 2011, pp. 7-30). Tras concluir las negociaciones, la Presidencia del Consejo de la Unión designó al representante permanente húngaro ante Naciones Unidas para la firma del acuerdo el 10 de junio de 2011 en nombre de la UE, habida cuenta de que Hungría mantenía en aquel semestre la Presidencia del Consejo. Aunque los Estados miembros de la UE gocen del estatuto de miembro pleno en la OIC, es el Consejo de la UE, representado por su Presidencia, quien lo hace en su nombre. (Información sobre la OIC aportada a título individual por el director ejecutivo de la OIC, Michael Arrion, a la autora.) 
votación, presupuestos y representación orgánica, entre otros) necesarios para la continuación de la UE y del RU (en su condición de miembros) de forma acorde con las reglas de la organización internacional, pero desligándose este de la Unión en su actividad dentro de la OIC.

En cuanto al voto, en la práctica institucional es la Comisión Europea, en nombre de la Unión, quien ejerce este derecho con «un número de votos igual al total de los votos atribuible a sus Estados miembros de conformidad con el artículo 10» (arts. 4.6 y 10.6 del convenio 2010). De forma que el volumen medio de importaciones de granos de cacao fijados de acuerdo con el art. $10.3^{53}$ del convenio de 2010 será el que la OIC tendrá en cuenta para atribuir al Reino Unido el número de votos que le corresponda, ya de forma independiente, detrayendo este número del que le correspondía a la UE antes de la retirada del RU ${ }^{54}$.

De forma similar al ejercicio del derecho de voto, es la UE quien contribuye al presupuesto de la OIC, y no los Estados miembros de la Unión. La contribución se fija atendiendo al número de votos asignados a cada miembro (art. 24.2 del convenio de 2010). De esta forma, la retirada del RU de la UE tiene como consecuencia que este Estado será el que cumpla con la obligación de contribución presupuestaria de forma independiente en la proporción fijada de acuerdo con los votos que se le asignen. Consecuentemente, la cantidad abonada por UE por este concepto menguará proporcionalmente a lo aportado por el RU al presupuesto administrativo de la OIC.

En cuanto al derecho de estar representado en las reuniones de los órganos de la OIC, es el Consejo de la UE quien informa a la secretaría de aquella organización del personal acreditado que integrará la delegación de la UE (procedente de la representación del Estado que ejerce la Presidencia del Consejo de la Unión ese semestre, de los Estados miembros y de la Comisión), por ejemplo, a las reuniones ordinarias del Consejo Internacional del Cacao (arts. 6.2 y 9 del convenio de 2010 citado). Como consecuencia del Brexit, por tanto, el RU deja de formar parte de la delegación de la Unión en los órganos de la OIC, pudiendo este Estado participar a título individual.

Durante los debates, suele ser la Comisión Europea la que toma la palabra en primer lugar, fijando los puntos de vista de la UE. No obstante, también puede hacerlo el representante del Estado que ejercer la Presidencia

53 A la firma de este convenio de 2010, el Reino Unido tenía un promedio de importaciones de cacao calculadas de acuerdo con el art. 57 (y art. 10.3), de $4.76 \%$, siendo el de la UE de 53,24\% (anexo B del convenio).

54 El encargado de realizar esta redistribución de votos es el Consejo Internacional del Cacao (art. 10.6 del convenio de 2010). 
del Consejo o cualquiera de los Estados miembros. En la práctica institucional, los Estados miembros de la UE pueden adoptar un papel activo en las reuniones de los órganos, se les identifica en su doble condición de miembros de la UE y Estados autónomos con sus singularidades e intereses propios. El RU, tras su salida de la UE, habla y adopta una posición ya exclusivamente en su nombre como Estado soberano independiente, y no como parte del club comunitario. Finalmente, en la selección de los presidentes y vicepresidentes que dirigen los órganos estatutarios (Consejo Internacional del Cacao o de los comités) pueden ser elegidos entre otros representantes, bien de la Comisión Europea o bien de los Estados miembros de la UE. Por lo que los nacionales británicos que presenten su candidatura a estos órganos, tras su retirada, lo hacen a título individual estatal y no en su calidad de representantes de la UE.

En definitiva, si bien es cierto que las adaptaciones comentadas en el seno de esta organización internacional de productos de base como consecuencia de la retirada del Reino Unido de la UE son específicamente para ella, este patrón operativo que hemos desgranado en base a su tratado constitutivo se reproduce de forma similar en otros organismos internacionales.

\section{b) El caso de la FAO}

Este organismo especializado de las Naciones Unidas constituye uno de los ejemplos paradigmáticos en los que participan con la condición de miembro conjuntamente la UE y todos sus Estados miembros. Con la retirada del RU de la UE, ambos mantienen su respectiva membresía. En la FAO, como en muchas otras organizaciones internacionales de esta categoría de participación conjunta, existe una alternancia en el ejercicio de los derechos en el ámbito de sus respectivas competencias entre la UE y sus Estados miembros — que lo son también de la FAO_ ${ }^{55}$. Dicha alternancia se organiza a través de declaraciones de competencias en las materias tratadas, tanto en el momento de la solicitud de adhesión a la FAO (art. II.5) como específicas antes de cada reunión ad hoc. Con el Brexit, la UE dispondrá de un voto menos (veintisiete en vez de veintiocho) cuando sea ella la competente para ejercer dicho derecho; mientras que el RU recuperará su voto, que ejercerá de forma independiente,

55 Art. II.8 de la Constitución de la FAO de 16 de octubre de 1945, reformada posteriormente en 1991 para permitir la adhesión de OIER, como la actual UE, antigua Comunidad. Para un análisis pormenorizado de los efectos jurídicos de la actividad de la FAO sobre uno de sus miembros que se retira de la UE véase Oanta (2020a: 284-300). 
por su propio derecho y de acuerdo a sus intereses como Estado, también en ámbitos competenciales de la Unión - de la que ya no forma parte ${ }^{56}$.

Los efectos jurídicos que pueden producirse en la actividad de esta organización internacional sobre el Reino Unido pueden ser variados. Entre otros, se identifican ciertas consecuencias negativas transitorias para el Estado saliente, ya que «durante un periodo relativo de tiempo estará infrarrepresentado en diversos organismos existentes en el marco de la FAO», en alusión a aquellos creados por este organismo en los que participa únicamente la UE, como el Comité de Pesca para el Atlántico Centro-Oriental (CEPACO) o la Comisión General de Pesca en el Mediterráneo (CGPM). Por ello, el Estado retirado deberá «reactivar ciertos aspectos de su representatividad internacional (Oanta, 2020: 937, 931-945) —lo que hará el RU si no se regula de otra manera en un acuerdo UE-RU post-Brexit-, manifestando su consentimiento en obligarse por los acuerdos constitutivos de los organismos citados supra.

En relación con los acuerdos ratificados únicamente por la UE en el ejercicio de su competencia exclusiva, sus disposiciones no serán aplicables al RU, desde la expiración del periodo transitorio del Acuerdo de Retirada (art. 217.1 AR) —salvo que el acuerdo UE-RU post-Brexit establezca otra cosa-. El RU debería "promulgar nueva legislación substancial»; no obstante, «sería imposible un aislamiento completo de dicho Estado frente a los efectos del acervo de la UE», por ejemplo, en materia de agricultura, alimentación y pesca (Oanta, 2020: 942-943). El RU podría, según esta autora, adoptar una legislación nacional para cubrir el vacío jurídico o ratificar los tratados - lo que parece más probable.

c) El caso de la OMC

En la Organización Internacional del Comercio, tanto la UE como el RU mantendrán su condición de miembro, si bien este último pasará a ejercer todas las competencias que le corresponden como miembro de pleno derecho. Se han planteado dos cuestiones, inicialmente polémicas, que pasamos a comentar. Primero, enlazando con lo ya señalado en relación con la FAO, también en la $\mathrm{OMC}$, la cuestión relativa a los acuerdos concluidos en su seno únicamente por la UE, sin sus Estados miembros - y, por tanto, sin el RU como parte- al tener la Unión competencia exclusiva en la política comercial común, ha resultando controvertida. Algún autor ha mostrado su apoyo a

56 De forma similar ocurrirá, por ejemplo, en la Agencia Internacional de Energías Renovables (IRENA) al contemplar dicha fórmula para las OIER (la UE, sin citarla expresamente) y sus Estados miembros (Art. VI.C de su Estatuto). 
la sucesión por parte del RU en aquellos acuerdos ${ }^{57}$. Este planteamiento es rechazado por otra parte de la doctrina - a la que nos adherimos - ya que esta sucesión "forzada» presupone diluir en la práctica la personalidad jurídica internacional de la $\mathrm{UE}^{58}$. El segundo ejemplo no pacífico en el marco de la $\mathrm{OMC}$ es el que muestra las dificultades que está provocando el reparto de los contingentes arancelarios entre el Reino Unido y la UE ${ }^{59}$. Una consecuencia colateral para el RU en la OMC derivada del Brexit es el reforzamiento intenso que requiere su representación estatal acreditada ante esta organización internacional, habida cuenta de que perderá el soporte que realiza la delegación de la UE acreditada en Ginebra — desde 2011 de forma específicamente ante la OMC, con la creación del SEAE- (Bosse-Platière, 2016: 759; Kaddous, 2015; Pérez Bernárdez, 2011: 85-97). La futura relación comercial de la UE y del RU en la OMC vendrá marcada por la naturaleza del acuerdo de libre comercio que se concluya en su caso.

\section{ii) Participación conjunta en calidad de miembro de la UE y del Reino Unido unicamente en relación con sus territorios dependientes en una organización inter- nacional.}

Se trata de un supuesto con similitudes respecto al caso anterior (i), pero con consecuencias jurídicas que difieren del primero. Este sería el caso, por ejemplo, del RU en su condición de miembro en ciertas OROP en relación

57 En concreto, en relación con el acuerdo plurilateral de contratación pública (ACP o GPA, de 2014), que tiene como objeto la apertura mutua de los mercados de contratación pública entre sus partes (Bartels, 2018). En relación con este ACP, un plan de contingencia por parte de la UE en el contexto de la retirada del RU ya recoge la posición propuesta en nombre de la UE ante su Comité. Véase: Comisión Europea, Propuesta de Decisión del Consejo, $\operatorname{COM}(2019) 46$ final/2, Bruselas, 1.3.2019. Sobre el proceso y buen hacer negociador del RU con la UE, entre otros miembros, en relación con el ACP, véase Messenger (2020: 137-138).

58 Tampoco está clara la posible aplicación por analogía de la Convención de Viena sobre Sucesión de Estados en materia de Tratados de 23 de agosto de 1978 —en vigor desde 1996 - o de normas consuetudinarias internacionales sobre la sucesión para mantener aquel planteamiento. Lazowski y Wessel (2016: 623); Odermatt (2017: 1057).

Algunos países terceros están demandando compensaciones porque se sienten perjudicados con el nuevo reparto propuesto: Barfield (2018); Messenger (2020: 136, 139 140). Véase el Reglamento (UE) 2019/216 del Parlamento Europeo y del Consejo, de 30 de enero de 2019, relativo al reparto de los contingentes arancelarios incluidos en la lista de la OMC para la Unión, a raíz de la retirada del Reino Unido de la Unión (DO L 38, 8.2.2019, pp. 1 y ss.). 
exclusivamente a las Islas Turcas y Caicos — no cubiertas por el TFUE— ${ }^{60}$. En concreto se da en la Comisión Internacional para la Conservación del Atún del Atlántico (CICAA-IATTC) o en la Comisión del Atún del Océano Índico (CAOI-IOTC) en las que el RU participa, hasta su retirada de la UE, solo parcialmente en relación con estos territorios de ultramar no cubiertos por los Tratados. Tras el periodo transitorio se valería de dicho estatuto para seguir ejerciendo su condición de miembro, asumiendo mayores competencias - las anteriormente ejercidas por la UE - con los ajustes en derechos de voto, uso de la palabra y obligaciones presupuestarias, de acuerdo con lo estipulado en el tratado constitutivo de la OROP en cuestión. No tendrá, por tanto, que solicitar su nueva adhesión a la organización internacional. El RU, a nivel de representación en el organigrama institucional, de derechos y obligaciones inherentes a la condición de miembro, necesita de ajustes más intensos respecto del supuesto anterior (i), habida cuenta de su participación anterior más limitada como miembro en la organización internacional concernida.

iii) Participación exclusiva de la UE en calidad de miembro en una organización internacional, asumiendo aquella la de sus Estados miembros (entre ellos el Reino Unido hasta su retirada de la Unión) y, por ende, sin contar estos con un estatuto de miembro en la organización.

En esta categoría nos encontramos con ciertas organizaciones internacionales, que no son muy abundantes, generalmente de carácter técnico y que gestionan materias en las que la UE posee fundamentalmente una competencia exclusiva, por lo que esta participa con exclusión de sus Estados miembros en la organización, asumiendo su representación ${ }^{61}$. El Reino Unido en tanto que Estado miembro de la Unión - hasta su retirada - tiene un interés en la actividad desarrollada en la organización internacional en cuestión, y quedaba afectado de forma indirecta por los derechos y obligaciones a través de la UE. Por lo tanto, su salida de la UE le obliga a plantearse su participación en

60 Como Francia en relación con Saint Pierre y Miquelón o Dinamarca en relación con las Islas Feroe o Groenlandia en la OCSAN; Heckler (2019: 435).

61 El ejemplo típico de organizaciones internacional en las que se da esta participación exclusiva de la Unión son las de pesquerías y las dedicadas a ciertos productos básicos. En relación con las OROP, estarían la CPANE — comentada supra-, la OCSAN o la CCARS. Entre las dedicadas la gestión de productos básicos se encuentran el Consejo Oleícola Internacional — que analizamos con mayor detalle infra-, el Consejo Internacional del Azúcar o el Consejo Internacional de Cereales. Sobre la retirada de un Estado de una organización internacional y sus efectos en la membresía de ambos en las organizaciones regionales de ordenación pesquera a la luz del Brexit, véase Oanta (2020a: 301-332). 
calidad de Estado miembro de la organización, si quiere seguir disfrutando de los mismos derechos y obligaciones.

Para que este tipo de participación exista, la organización internacional en cuestión ha tenido que tener en cuenta la naturaleza jurídica especial de la Unión en su tratado constitutivo fundacional, bien desde la creación de la organización o reformándolo a posteriori. La retirada del Reino Unido de la UE no altera la condición de miembro de la UE en la organización internacional, que se mantiene sin que sus Estados miembros lo sean. Por su parte, el Reino Unido — si lo estima adecuado de acuerdo con sus intereses y la organización internacional en cuestión lo permite según lo estipulado en sus reglaspodría solicitar la condición de Estado miembro. El proceso de admisión puede demorarse más o menos dependiendo de la complejidad del mismo. Cuando hay voluntad política para que esta adhesión se produzca —inclusive por parte de la UE y de terceros Estados participantes en la organización internacional-, las amplias mayorías o incluso unanimidad requeridas en el órgano decisorio competente para adoptar una resolución que dé luz verde a la solicitud de la condición de miembro no suelen encontrar problemas. El RU con una sólida diplomacia será generalmente un miembro bienvenido por su capacidad y amplia contribución financiera a la organización a la que desee adherirse.

Los acomodos institucionales a realizar en la organización en cuestión - y para la propia Unión en el ejercicio de sus derechos y obligacionesson aquí más intensos que en los supuestos anteriores, si el RU se adhiere como Estado miembro a la misma. Deberán modificarse cuestiones relativas a su presencia en órganos, al voto y presupuesto, entre otros. Un aspecto que tendrá que ser evaluado en el futuro para determinar el impacto del Brexit será cómo afecta al peso efectivo de la UE en las organizaciones internacionales incluidas en esta categoría. Pongamos un ejemplo de una organización concreta que responde a las características que acabamos de describir.

d) El caso del Consejo Oleícola Internacional

Esta organización internacional sobre productos básicos gestiona el Convenio Internacional del Aceite de Oliva y de las Aceitunas de Mesa de $2015^{62}$. Se encuentra integrada por diecisiete miembros, que representan el $95 \%$ de la producción oleícola mundial (dieciséis Estados y la UE, a la que

62 El convenio entró en vigor con carácter provisional el 1 de enero de 2018 (DO, L 293, 28 de octubre de 2016, pp. 3 y ss.). 
alude expresamente junto a otras «organizaciones intergubernamentales» el art. 4.3 del convenio de 2015 citado) $)^{63}$.

Reino Unido, como Estado soberano ya retirado de la UE, es muy probable que solicite, asimismo, su adhesión a esta organización, de la que fue miembro fundador en 1958, quedando posteriormente su membresía sin efecto al incorporarse la UE en 2016 al Consejo Oleícola Internacional (COI) - como le ocurrió a España, entre otros- ${ }^{64}$. Será el Consejo de Ministros de esta organización internacional el que determine las condiciones de adhesión de un Estado al convenio de 2015 (art. 29). Una de las cuestiones claves de la que es competente aquel órgano es la determinación de la cuota de participación que le corresponde al RU en su caso ${ }^{65}$. Las cuotas asignadas son relevantes ya que determinan las contribuciones financieras al presupuesto y los derechos de voto de los miembros (art. 11) ${ }^{66}$. Además, las decisiones del COI, pese a no tener carácter jurídicamente vinculante per se, sí que producen efectos jurídicos en la UE, en el sentido confirmado por la jurisprudencia del TJUE en relación con el art. 218.9 TFUE ${ }^{67}$.

63 El número de Estados miembros en el Consejo Oleícola Internacional (COI) ha aumentado en los últimos tiempos. De hecho, Georgia acaba de incorporarse a esta organización internacional con el beneplácito de la UE y otro Estado, Uzbekistán, ha solicitado su adhesión y es probable que se incorpore como Estado número dieciocho. En relación con Georgia, Decisión (UE) 2019/1017 del Consejo, de 14 de junio de 2019, relativa a la posición que debe adoptarse en nombre de la Unión en el Consejo de Ministros del Consejo Oleícola Internacional en lo que respecta a las condiciones de la adhesión del Gobierno de Georgia al Convenio Internacional del Aceite de Oliva y de las Aceitunas de Mesa de 2015 (DOL 165, 21 de junio de 2019, pp. 66 y ss.)

64 La UE se adhirió al COI en calidad de miembro tras firmar el Convenio Internacional del Aceite de Oliva y de las Aceitunas de Mesa de 2015 de conformidad con la Decisión (UE) 2016/1892 del Consejo, el 18 de noviembre de 2016 en la sede de las Naciones Unidas en Nueva York.

65 Esta operación tiene en cuenta que todos los miembros de la organización poseen conjuntamente mil cuotas y que estas se reparten de acuerdo con una fórmula fijada en el convenio de 2015. A título informativo, en 2015 la UE en el COI contaba con 717, siendo el segundo miembro con un número mayor Túnez, con 67 (Anexo A del Convenio de 2015).

66 La contribución al presupuesto anual (art. 16) y el número de votos de cada miembro en la toma de decisiones estarán condicionados por las cuotas que posee (art.10), lo que tiene un carácter relevante si las decisiones no se adoptan por consenso.

67 Sentencia de 7 de octubre de 2014, OIV, citada, apdo. 64. Véanse las notas 10 y 22. 
iiii) Participación de la UE como observadora en una organización internacional en la que sus Estados miembros (o algunos) gozan de la condición de miembro (entre ellos el Reino Unido).

Una de las consecuencias para el Reino Unido, en su condición de miembro en una organización internacional en la que la UE participa de forma restringida - por ejemplo, en calidad de observador- es que aquel queda liberado de coordinarse a través de reuniones u otros instrumentos con Estados miembros de la Unión —que también lo sean de la organización en cuestión- y con los representantes de la propia Unión, en asuntos de interés mutuo, con el objeto de encontrar posiciones o estrategias comunes. Dejará de utilizar el apoyo logístico que ofrecen a tal fin las delegaciones de la UE acreditadas ante organizaciones internacionales. Asimismo, el RU, como participante pleno en una organización internacional en la que otros miembros de la UE y esta no se encuentran representados, deja de quedar obligado a intercambiar información — desde su retirada de la Unión - con esta y con el resto de sus Estados miembros ${ }^{68}$. Son numerosas las organizaciones internacionales en las que el RU es Estado miembro y la UE goza en algunos de sus órganos de la condición de observadora — privilegiada $-{ }^{69}$. Con un estatuto de

68 Por ejemplo, en el marco de la PESC, informando al Alto Representante de la UE para Asuntos Exteriores y Política de Seguridad y en relación con el CSNU específicamente (art. 34.2 TUE). Las dinámicas del RU en el CSNU tendrán una relevancia singular, al perder la UE a uno de sus dos únicos Estados miembros con la condición de permanentes en este órgano y quedando Francia como único Estado miembro con estatuto privilegiado con derecho de veto ante la adopción de decisiones jurídicamente vinculantes en ámbitos claves relativos al mantenimiento de la paz y la seguridad internacionales (arts. 25, 27 y 39 y ss. del cap. VII de la Carta de las Naciones Unidas). A Francia se suman otros tres Estados europeos como miembros no permanentes en el CSNU: Alemania y Bélgica (hasta finales de 2020), Estonia (que termina su mandato un año después) y para el bienio 2021-2022, Irlanda y Noruega (esta como Estado europeo no miembro de la Unión, pero sí de la OTAN). Identificando cierto debilitamiento de la influencia del RU ante las Naciones Unidas debido en parte al Brexit, véase Wouters (2020: 148 y 156).

69 Entre ellos, OMS, OIT, FMI, Banco Mundial, OMPI, OACI, UNESCO, OCDE, Consejo de Europa, OSCE, OIV, Agencia Espacial Europea, Asamblea General de las Naciones Unidas, Comité de Políticas y Programas de Asistencia Alimentaria del Programa Mundial de Alimentos (CAA, FAO/ OMS), Conferencia de las NU para el Comercio y el Desarrollo (UNCTAD), Comisión de las Naciones Unidas para el Derecho Mercantil Internacional 
observador sin este carácter reforzado se encuentra la UE en otros tantos organismos y foros ${ }^{70}$.

Dentro de este tipo de participación en el que la UE no es miembro de la organización internacional se plantean dificultades adicionales en relación con los acuerdos celebrados por los Estados miembros en nombre de la UE, teniendo en cuenta que el RU continuaría como parte, en su propio derecho. Ahora bien, la implementación de estos acuerdos en ocasiones se enmarca en políticas y normas de la UE. Así, en acuerdos internacionales multilaterales concluidos en el marco de organizaciones internacionales, como la OMI, la OACI o OIT ${ }^{71}$, entre otras, en las que el RU es miembro y la UE no lo es, más bien parece que los Estados de la Unión - y Reino Unido, por extensión durante el periodo transitorio- actúan como agentes de la UE. El método sobre cómo se producirá la desvinculación británica tras esta fase transitoria será uno de los escollos jurídicos a resolver ${ }^{72}$.

\section{e) ¿Un Reino Unido alineado a la UE?}

Un aspecto a analizar de cara al futuro serán las dinámicas de actuación del RU, la UE y sus Estados miembros en las organizaciones internacionales, verificando si aquel Estado, pese a ser ya un tercero para la UE, sigue alineando su posición con la UE y sus Estados miembros, como ha sido frecuente en la práctica actual en ciertas organizaciones internacionales, habida cuenta de los intereses y valores comunes que existen entre todos ellos. Los ámbitos materiales tratados condicionarán dichas alianzas (derechos humanos, democracia y

(UNCITRAL), el Consejo de Derechos Humanos de NU o OMPI. Sobre los efectos del Brexit en los acuerdos administrados en esta última — sistema de La Haya para el registro de dibujos y modelos industriales- véase Bontekoe y Wallot (2019: 291-292).

70 Entre ellos, OIEA, Comisión Ballenera Internacional, Comisión de Venecia y el Grupo de Estados para la Corrupción —ambos en el marco del Consejo de Europa-, UNICEF, ECOSOC de Naciones Unidas o en el Consejo Ártico — en el que el Reino Unido es observador.

71 Véase, Dictamen 2/91, de 19 de marzo de 1993, OIT, citado en nota 10, apdo. 37.

72 En este sentido, la declaración del Tribunal Internacional del Derecho del Mar es ilustrativa, Request for Advisory Opinion submitted by the Sub-Regional Fisheries Commission, Advisory Opinion, 2 April 2015, ITLOS, Case No. 21, para. 172, p. 51. Wessel (2018: 127-128). 
Estado de derecho ${ }^{73}$, por un lado, seguridad y defensa ${ }^{74}$, comercio, pesquerías, etc.). Así, en la PESC, pese a la voluntad británica de seguir vinculada a ella, el RU es, con todo el peso del término jurídico, un «tercer Estado» al que no puede imponérsele obligaciones a través de un tratado sin su consentimiento, y participar en ciertas políticas supone, en definitiva, asumir obligaciones en ámbitos en los que ya ha dejado de tener capacidad de influir, como en la adopción de normas europeas de implementación, al no tener la condición de miembro de la $\mathrm{UE}^{75}$. De hecho, el régimen de participación restringida para terceros en la propia UE y sus órganos es extremadamente limitado ${ }^{76}$. En otro ámbito material clave para los intereses de la Unión, como el que gestionan

73 El hecho de que Reino Unido tenga la condición de tercer Estado no impide que se sume a la Unión, como hacen otros Estados en ciertos órganos u organizaciones internacionales; por ejemplo, los integrantes del Espacio Económico Europeo, como Noruega o Islandia, en temas vinculados a derechos humanos en el seno de la AGNU o en el Consejo de Derechos Humanos, en caso de participar en este último.

74 Por ejemplo, en el ámbito de la seguridad y defensa común, la posición oficial británica ha sido contundente al defender su compromiso con la UE y la necesidad de mantener el reforzamiento de esta con la OTAN (UK, 2017: 22). Véase también Wright et al. (2020: 53-54).

75 Art. 34 Convención de Viena del Derecho de los Tratados. Una disposición que constituye, asimismo, una norma consuetudinaria internacional, como el TJUE ha reconocido en el asunto Brita, Sentencia de 25 de febrero de 2010, C-386/08, EU:C:2010:91, apdo. 44.

76 En las instituciones comunitarias no se admiten observadores de forma oficial, si bien es posible que, de manera excepcional y examinando cada caso, se abran determinadas formaciones a terceros, es decir, a Estados — como podría ser el RU en el Consejo de la Unión-. Efectivamente, las disposiciones de la PESC no contemplan la participación en el proceso de adopción de decisiones a Estados no miembros (como se infiere del art. 28.2 TUE). Tal como clarifican las observaciones al art. 6 del Reglamento interno del Consejo Europeo y del Consejo de la Unión de 2016, pp. 39-40, las limitaciones de la presencia ocasional de representantes o de observadores oficiosos (por ejemplo, británicos) a sus trabajos son bien amplias, debiendo el Consejo autorizar su presencia en relación con cada punto específico del orden del día. Sobre las restricciones que impone el derecho de la Unión e internacional a esta potencial relación especial de la UE y el RU en el marco de la PESC a modo de "friends with benefits» (Wessel, 2019: 433). En el reverso de este contexto, la oportunidad que supone para la UE la consolidación de una política exterior propia y autónoma, como consecuencia del Brexit, ha sido puesta en valor tempranamente (Aldecoa Luzárraga, 2017: 37). Este último escenario posicionaría con mayor solidez a la UE para desarrollar una de sus raisons d'être, su liderazgo ante los desafíos globales (Búrca, 2014: 37), también en el seno de las organizaciones internacionales. 
las OROP y otras organizaciones dedicadas a aspectos diversos de los mares y océanos existe incertidumbre sobre el posicionamiento británico, que pudiera dar lugar a otras alianzas que cultural e históricamente se encuentran más próximas al mundo anglosajón «y no siempre compatibles con las posturas de la UE», lo que podría tener consecuencias negativas debilitando la presencia europea $^{77}$.

\section{REFLEXIONES FINALES}

El Brexit es el ejemplo más complejo de retirada de una organización internacional hasta el momento. Este hecho ha generado el proceso de desconexión más extenso de todos los que han tenido lugar en la práctica institucional internacional. La condición de miembro de la Unión implica una gran cantidad de derechos y obligaciones, con efectos político-jurídicos vastos, atendiendo tanto a las materias como a los sujetos concernidos, al abandonar el Reino Unido una organización de integración regional con un sistema jurídico extremadamente enraizado en los ordenamientos de sus Estados miembros. Los planes de contingencia lato sensu adoptados en el contexto de organizaciones internacionales, especialmente por la UE, ante la posibilidad, primero, de una retirada abrupta y, segundo, de no alcanzar un acuerdo UE-RU de partenariado que regule sus relaciones mutuas a la finalización del periodo transitorio a partir de 2021, ponen de relieve los amplios recursos humanos y económicos empleados no invertidos en otros asuntos de interés para la Unión, el Reino Unido y sus ciudadanos en general. Su impacto constituye un aviso a navegantes.

Con independencia de lo establecido en el posible acuerdo UE-RU de partenariado post-Brexit, tanto para el RU como para la UE, impulsar y realizar los ajustes específicos en las organizaciones internacionales en las que participan de acuerdo con sus reglas respectivas constituye un cometido obligado. De modo que, dependiendo de cada supuesto, deberán revisarse las manifestaciones inherentes a la condición de miembro (derechos de presencia y de expresión en los órganos de la organización internacional, derecho de voto o la obligación de contribuir al presupuesto), activar competencias que antes ejercía la Unión en el ámbito de actuación de la organización internacional, solicitar incluso la adhesión el Reino Unido, reforzar su representación

77 Sobrino Heredia (2016: 90, 88). Este autor se refiere más concretamente hacia un posible «deslizamiento hacia posicionamientos más medioambientalistas y conservacionistas en cuestiones como artes de pesca o zonas de pesca» (2018: 840-841). 
acreditada ante ciertas organizaciones y dejar de informar o de acudir a reuniones de concertación con representantes de los Estados miembros y de la Unión con el fin de adoptar posiciones comunes. El examen de las distintas categorías de participación de la UE y del RU en organizaciones internacionales (UE de forma exclusiva como miembro, conjunta con sus Estados miembros o como observadora), así como el análisis más detallado realizado en alguna de ellas, muestran ciertas pautas previsiblemente aplicables en cada categoría. Habrá que tener presente, no obstante, tanto las especificidades de las organizaciones — cada una con su propio marco jurídico-, como otros condicionantes (intereses económicos y políticos) que influyen en este proceso de adaptación institucional.

Concluimos afirmando que no creemos que la retirada del RU de la UE suponga un cambio profundo - $\mathrm{O}$ radical — en gran parte de las relaciones de la UE con las organizaciones internacionales, como hemos venido analizando. La UE tendrá que efectuar y supervisar aspectos técnicos con consecuencias materiales (voto o presupuesto) derivados de los ajustes a realizar en las organizaciones, hacer frente a la posible pérdida de peso en ciertos organismos (pesquerías o productos básicos) y velar por la obligación de cooperación leal entre los Estados miembros y la Unión para mantener la unidad en la representación internacional de la Unión - ya sin el RU, que como Estado miembro ha mantenido un comportamiento ocasionalmente díscolo en sus relaciones con la Unión durante el casi medio siglo de convivencia comunitaria-. Aun así, la UE se encuentra en una posición destacada en las organizaciones internacionales en las que participa - que ha ido consolidando progresivamente en sus Tratados originarios y a través de la jurisprudencia, como pone de relieve la práctica - para adaptarse y consolidarse como actor internacional. La UE podrá seguir jugando un papel crucial en la defensa del multilateralismo institucional en el futuro, a pesar de las incomodidades y tensiones que pueda generar el Brexit.

\section{Bibliografía}

Aldecoa Luzárraga, F. (2017). Relevancia del Brexit, problema y oportunidad para la Unión Europea y su política exterior. La Albolafia: Revista de Humanidades y Cultura, 12, 33-54.

Amtenbrink, F. y Kochenov, D. (2014). Messianism, mission or Realpolitik? Some Concluding Observations on the EU's role in shaping the International Legal Order. En D. Kochenov, F. Amtenbrink (eds.). The European Union's Shaping of the International Legal Order (pp. 349-360). Cambridge: Cambridge University Press. Disponible en: https://doi.org/10.1017/CBO9781139519625.020. 
Barbé Izuel, E. (2012). La UE en el contexto internacional, a la hora de las potencias emergentes. En E. Barbé (coord.). Cambio Mundial y Gobernanza Global. La interacción entre la Unión Europea y las instituciones internacionales (pp. 46-66). Madrid: Tecnos.

Bartels, L. (2018). The UK's Status in the WTO After Brexit. En R. Schütze y S. Tierney (ed.). The UK and the Federal Idea (pp. 227-250). London: Hart Publishing.

Barfield, R. (2018). UK Trade and the World Trade Organization. Disponible en: https://bit.ly/32Vr3nr.

Beqiraj, J. Gauci, J. P., Khalfaoui, A. (2019). United Nations High Commissioner for Refugees (UNHCR) and International Organization for Migration (IOM). En R. A. Wessel, J. Odermatt (eds.). Research Handbook on the European Union and International Organizations (pp. 2013-221). Cheltenham: Edward Elgar Publishing. Disponible en: https://doi.org/10.4337/9781786438935.00017.

Bontekoe, E. y Wallot, M. (2019). World Intellectual Property Organization (WIPO). The growing presence of the $\mathrm{EU}$ in formulating international intellectual property law. En R. A. Wessel, J. Odermatt (eds.). Research Handbook on the European Union and International Organizations (pp. 275-292). Cheltenham: Edward Elgar Publishing. Disponible en: https://doi.org/10.4337/97 81786438935.00022 .

Bosse-Platière, I., Flaesch-Mougin, C., Delcourt, Ch., Hamonic, A., Rapoport, C. (2016). Brexit et action extérieure de la l'Union européenne. Revue Trimestrielle de Droit Européen, 52 (4), 759-785.

Brölmann, C. M., Collins, R., Droubi, S., Wessel, R. A. (2018). Exiting International Organizations. A brief introduction. International Organizations Law Review, 15, 243-263. Disponible en: https://doi.org/10.1163/15723747-01502001.

Castellarin, E. (2019). World Bank Group (IBRD), International Monetary Fund (IMF) and European Bank for Reconstruction and Development (EBRD). The EU's participation in the global financial world. En R. A. Wessel, J. Odermatt (eds.). Research Handbook on the European Union and International Organizations (pp. 293-315). Cheltenham: Edward Elgar Publishing. Disponible en: https://doi.org/10.4337/9781786438935.00023.

Cinelli, C. (2019). Law of the Sea Framework. Is EU engagement a sine qua non for influence? En R. A. Wessel, J. Odermatt (eds.). Research Handbook on the European Union and International Organizations (pp. 462-482). Cheltenham: Edward Elgar Publishing. Disponible en: https://doi.org/10.4337/978178643 8935.00032 .

Costa, O. y Jørgensen, K.E. (2012), The Influence of International Institutions on the EU. When Multilateralism hits Brussels. Hamphire: Palgrave Macmillan.

De Búrca, G. (2014). Europe's raison d'être. En F. Amtenbrink y D. Kochenov (eds.). The EU's shaping of the International Legal Order (pp. 21-37). Cambridge: Cambridge University Press. Disponible en: https://doi.org/10.1017/CBO9781139519625.004. 
Dougan, M. (2018). An Airbag for the Crash Test Dummies? EU-UK Negotiations for a Post-Withdrawal "status quo" Transitional Regime under article 50 TEU. Common Market Law Review 55, 57-100.

Emmerling, T. (2019). World Health Organization (WHO) and other global health bodies. The EU voice in a fragmented global health landscape. En R. A. Wessel, J. Odermatt (eds.). Research Handbook on the European Union and International Organizations (pp. 120-141). Cheltenham: Edward Elgar Publishing. Disponible en: https://doi.org/10.4337/9781786438935.00013.

Fahey, E. (2019). The legal effects of the EU's interaction with other international institutions in law. "Inwards", "outwards", and the "in-between". En R. A. Wessel, J. Odermatt (eds.). Research Handbook on the European Union and International Organizations (pp. 644-657). Cheltenham: Edward Elgar Publishing. Disponible en: https://doi.org/10.4337/9781786438935.00043.

Frid, R. (1995). The relations between the EC and International Organizations. Legal Theory and Practice. The Hague: Kluwer International Law.

González, M. (2020). Cuando un aliado encañona a otro. El País, 3-7-2020. Disponible en: https://elpais.com.

González Alonso, L. N. (dir.) y Garrido Muñoz, A. (coord.) (2011). La Unión Europea y el multilateralismo eficaz ¿un compromiso consistente con Naciones Unidas? Madrid: Iustel.

Govaere, I. (2014). Novel issues pertaining to EU Member States Membership of other International Organisations: The OIV case (pp. 225-243). En I. Govaere, E. Lannon, P. Van Elsuwege, S. Adam, M. Maresceau (eds.). The European Union in the World. Leiden: Nijhoff. Disponible en: https://doi. org/10.1163/9789004259140_014.

Gstöhl, S. (2009). Patchwork Power Europe: The EU's Representation in International Institutions. European Foreign Affairs Review, 14 (3), 385-403.

Heckler, P. (2019). Regional Fisheries Management Organisations. Defining the EU and Member State roles. En R. A. Wessel, J. Odermatt (eds.). Research Handbook on the European Union and International Organizations (pp. 429-445). Cheltenham: Edward Elgar Publishing. Disponible en: https://doi.org/10.433 7/9781786438935.00030.

Hinojosa Martínez, L. M. (2020). Los movimientos de capital y los servicios financieros en las relaciones con el Reino Unido y Gibraltar tras el Brexit: ¡seguridad jurídica o ley de la selva?. Cuadernos de Gibraltar-Gibraltar Reports, 4, 20202021. Disponible en: https://revistas.uca.es.

Kaddous, C. (ed.) (2015). The EU in International Organisations and Global Governance. Recent developments. Blomsbury: Hart publishing.

Klabbers, J. (2019). An Introduction to International Organizations Law. Cambridge: Cambridge University Press.

Koops, J. A. (2011). The EU as an Integrative Power? Assessing the EU's "Effective Multilateralism" Towards NATO and the United Nations. Brussels: Brussels University Press. 
Lazowski, A. y Wessel, R. A. (2016). The External Dimension of Withdrawal from the European Union. Revue des Affaires Europénnes, 2016 (4), 623-638.

Liñán Nogueras, D. J. (2020). La acción exterior de la Unión Europea (parte sexta). En A. Mangas Martín y D. J. Liñán Nogueras (eds.). Instituciones y Derecho de la Unión Europea (pp. 559-562). Madrid: Tecnos.

Messenger, G. (2020). EU-UK Relations at the WTO. Towards Constructive Creative Competition. En J. Santos, R. A. Wessel (eds.) y P. R. Polak (ass. ed.). The Routledge Handbook on the International Dimension of Brexit (pp. 135-147). London: Routledge. Disponible en: https://doi.org/10.4324/978100300297010 .

Miller, V. (2017). Legislating for Brexit: EU external agreements. London: House of Common. Disponible en: https://bit.ly/3pB6jLq.

Oanta, G. A. (2020). Participación de la Unión Europea en la FAO y los efectos de una eventual retirada de uno de sus Estados miembros. En J. M. Sobrino Heredia y G. A. Oanta (coord.). La construcción jurídica de un espacio marítimo común europeo (pp. 925-945). Barcelona: Bosch Editor. Disponible en: https:// doi.org/10.2307/j.ctv14t46t4.42.

- (2020a). La sucesión de Estados en las Organizaciones Internacionales: Examen de la práctica institucional. Barcelona: Bosch Editor.

Odermatt, J. (2017). Brexit and International Law: Disentangling Legal Orders. Emory International Law Review, 31, 1051-1073.

Odermatt, J. y Wessel, R. A. (2019). The challenges of engaging with international institutions. The EU and multilateralism under strain. En R. A.Wessel, J. Odermatt (eds.). Research Handbook on the European Union and International Organisations (pp. 658-672). Cheltenham: Edward Elgar Publishing. Disponible en: https://doi.org/10.4337/9781786438935.00044.

Pérez Bernárdez, C. (2011). Una visión desde el Derecho de la puesta en marcha de las nuevas Delegaciones de la Unión Europea. En F. Aldecoa Luzárraga y S. Clotas i Cierco (ed.). La Diplomacia Común Europea: El Servicio Europeo de Acción Exterior (pp. 85-97). Madrid: Marcial Pons.

- (2016). The Consistency of the European Union's Human Rights Policy at United Nations. En P. Eeckhout y M. López Escudero (eds.). The European Union's External Action in Times of Crisis (pp. 325-373). Oxford: Hart Publishing.

Pichot, E. y Delarue, R. (2019). International Labour Organization (ILO). A dynamic and result-oriented cooperation with the EU and its Member States. En R. A. Wessel, J. Odermatt (eds.). Research Handbook on the European Union and International Organizations (pp. 101-119). Cheltenham: Edward Elgar Publishing. Disponible en: https://doi.org/10.4337/9781786438935.00012.

Ramopoulus, T. (2019). The EU in the OIV and other international agricultural commodity bodies. En R. A. Wessel y J. Odermatt, (eds). Research Handbook on the European Union and International Organizations (pp. 446-461). Cheltenham: Edward Elgar Publishing. 
Remiro Brotóns, A. (1986). Las Relaciones Exteriores de las Comunidades Europeas. En E. García de Enterría, J. D. González Campos, S. Muñoz Machado (eds). Tratado de Derecho Comunitario Europeo, tomo III (pp. 637 y ss.). Madrid: Civitas.

Roldán Barbero, F. J. (1998). La participación de la Unión Europea en Organismos Internacionales. En F. Mariño Menéndez (ed.). Acción Exterior de la Unión Europea y Comunidad Internacional (pp. 243-271). Madrid: Boletín Oficial del Estado.

Sánchez Ramos, B. (2013). Strengthening the capacity of the Arctic Council: Is the permanent secretariat a first step? Arctic Yearbook, 2013, 264-279. Disponible en: https://arcticyearbook.com.

- (2017). La institucionalización de la cooperación en el Ártico: una mirada al Consejo Ártico. En M. Sobrino Prieto (ed.). Espacios polares y cambio climático: Desafios jurídico-internacionales (pp. 139-166). Valencia: Tirant lo Blanch.

Santos Vara, J. (2002). La participación de la Unión Europea en Organizaciones Internacionales. Madrid: Colex.

Schermers, H. G. y Blokker, N. (2018). International Institutional Law. Leiden: Martinus Nijhoff Publishers. Disponible en: https://doi.org/10.1163/ 9789004381650 .

Sobrino Heredia, J. M. (2010). La participación en las Organizaciones Internacionales. En M. Díez de Velasco (coord.). Las Organizaciones internacionales (pp. 88-100). Madrid: Tecnos.

- (2016). La retirada del Reino Unido de la Unión Europea y sus posibles consecuencias para el sector pesquero de Galicia. Instituto Universitario de Estudios Europeos «Salvador de Madariaga», Universidade da Coruña. Disponible en: http:// www.arvi.org.

- (2018). El mar y la UE: la necesidad de una política marítima integrada. Revista de Derecho Comunitario Europeo, 61, 835-849. Disponible en: https://doi. org/10.18042/cepc/rdce.61.01.

- (2020). El Espacio marítimo común europeo y la maraña del Brexit. En J. M. Sobrino Heredia y G. A. Oanta (coord.). La construcción jurídica de un espacio maritimo común europeo (pp. 281-299). Barcelona: Bosch Editor. Disponible en: https://doi.org/10.2307/j.ctv14t46t4.14.

UK (2017). HM Government, Foreign policy, defence and development: a future partnership paper, 12 September 2017. Disponible en: https://bit.ly/2Uxfo9U.

Van der Loo, G. y Blockmans, S. (2016). The Impact of Brexit on the EU's International Agreements. Centre for European Policy Studies. Disponible en: https:// bit.ly/2UCWw9k.

Vaugeois, M. (2019). International Civil Aviation Organisation (ICAO). The development of the position of the EU in international aviation. En R. A. Wessel, J. Odermatt (eds.). Research Handbook on the European Union and International Organizations (pp. 222-239). Cheltenham: Edward Elgar Publishing. Disponible en: https://doi.org/10.4337/9781786438935.00018. 
Vlastou-Dimopoulou, F. (2019). Organisation for Economic Co-operation and Development (OECD). The EU's position as a de facto member. En R. A. Wessel, J. Odermatt (eds.). Research Handbook on the European Union and International Organizations (pp. 316-337). Cheltenham: Edward Elgar Publishing. Disponible en: https://doi.org/10.4337/9781786438935.00024.

Wessel, R. A. (2016). You Can Check out Any Time You like, but Can You Really Leave? On 'Brexit' and Leaving International Organizations. International Organizations Law Review, 13, 197-209. Disponible en: https://doi.org/10.1163/1572374701302001.

- (2018). Consequences of Brexit for International Agreements Concluded by the EU and its Member States. Common Market Law Review, 55, 101-132.

- (2019). Friends with Benefits? Possibilities for the UK's Continued Participation in the EU's Foreign and Security Policy, European Papers, 4 (2), 427-445. Disponible en: www.europeanpapers.eu.

- (2019). The European Union's engagement with other international institutions. Emerging questions of EU and international law. En R. A. Wessel, J. Odermatt (eds.). Research Handbook on the European Union and International Organizations (pp. 2-24). Cheltenham: Edward Elgar Publishing. Disponible en: https://doi.org/10.4337/9781786438935.00006.

Wouters, J. (2020). Brexit and its Implications for the EU in the UN Security Council. En J. Santos, R. A. Wessel (eds.) y P. R. Polak (ass. ed.). The Routledge Handbook on the International Dimension of Brexit (pp. 148-164). London: Routledge. Disponible en: https://doi.org/10.4324/9781003002970-11.

Wouters, J. y Chané, A.-L. (2016). Brussels Meets Westphalia: The European Union and the United Nations En P. Eeckhout y M. López Escudero (eds.). The European Union's External Action in Times of Crisis (pp. 299-324). Oxford: Hart Publishing.

Wouters, J. y Meuwissen, K. (2013). European Union at the UN Human Rights Council. Multilateral Human Rights Protection Coming of Age. Leuven: Leuven Centre for Global Governance Studies. Disponible en: https://doi.org/10.2139/ ssrn.2363523.

Wright, G., Stojanovic, A., Klemperer, D. (2020). Influencing the EU after Brexit. London: Institute for Government. Disponible en: https://bit.ly/3pEhSla. 